\title{
THESIS
}

\section{EFFECTS OF WOODY VEGETATION ON SHALLOW SOIL MOISTURE AT A SEMIARID MONTANE CATCHMENT}

\author{
Submitted by \\ Devin Traff \\ Department of Civil and Environmental Engineering \\ In partial fulfillment of the requirements \\ For the Degree of Master of Science \\ Colorado State University \\ Fort Collins, Colorado
}

Fall 2013

Master's Committee:

Advisor: Jeffrey D. Niemann

Timothy R. Green

Greg Butters 


\begin{abstract}
EFFECTS OF WOODY VEGETATION ON SHALLOW SOIL MOISTURE AT A SEMIARID MONTANE CATCHMENT
\end{abstract}

Soil moisture plays an integral role in many ecohydrologic processes and applications, particularly in semiarid environments. While interactions between vegetation and soil moisture at greater depths are relatively well understood, less is known about soil moisture at depths of $5 \mathrm{~cm}$ or less. In this study we investigate the impact of woody vegetation on shallow soil moisture dynamics for forested and shrubland ecosystems in a semiarid montane catchment. Instrumentation was installed on a forested north-facing hillslope (NFS) and a south-facing hillslope (SFS) vegetated primarily by shrubs at three types of locations: open or intercanopy, under mountain mahogany (Cercocarpus montanus) shrubs, and under ponderosa pine (Pinus ponderosa) trees. Rain gauges and pyranometers were installed to assess the impact of interception and shading, while time-domain reflectometry (TDR) probes were inserted into the top $5 \mathrm{~cm}$ of the soil to monitor hourly soil moisture. The observations suggest that interception reduces throughfall to about $25-50 \%$ of rainfall under the mountain mahogany and ponderosa pines. Shading is important for all locations on the NFS (PET $\sim 20 \%$ of the SFS open location), but less shading occurs under the SFS mountain mahogany (PET $\sim 40 \%$ of the SFS open location). Shallow soil under all vegetation types is typically wetter than at the SFS open location for dry conditions and drier than the SFS open location for wet conditions. Average shallow soil moisture is higher under all vegetation types than in the open, suggesting that the shading effect is stronger than the interception effect for the conditions studied. 


\section{ACKNOWLEDGEMENTS}

I would like to thank to my advisor, Jeff Niemann, for his guidance, patience, and help throughout. I would also like to thank Steve Middlekauff for his tremendous help with the field instrumentation, Brandon Lehman, Kevin Werbylo, Nathan Alburn, and Mike Coleman for their insightful recommendations, Samir Sahasrabudhe for collecting the soil data, and Tim Green and Greg Butters for serving on my committee. I also thank the Army Research Office Terrestrial Sciences Program, the Army Small Business Innovative Research Program, and the Center for Geosciences/Atmospheric Research for their financial support. 


\section{TABLE OF CONTENTS}

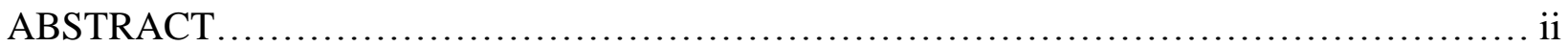

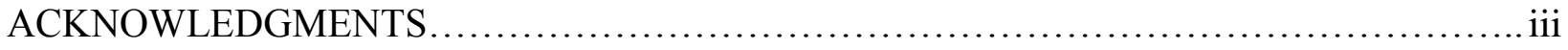

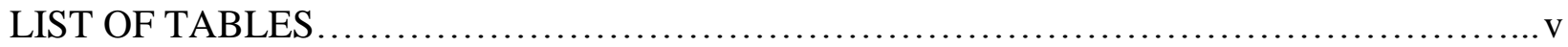

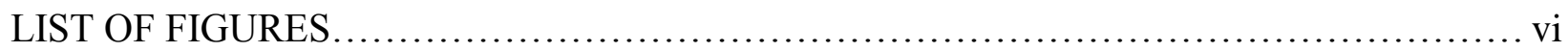

CHAPTER 1 INTRODUCTION........................................................ 1

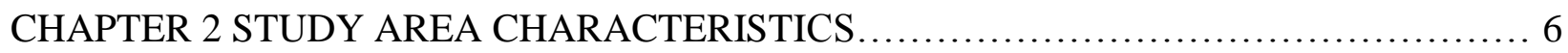

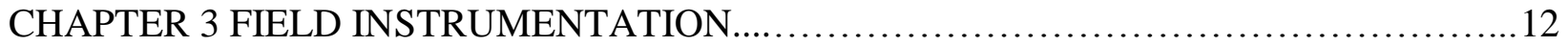

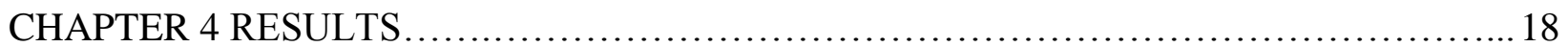

4.1 Throughfall......................................................... 18

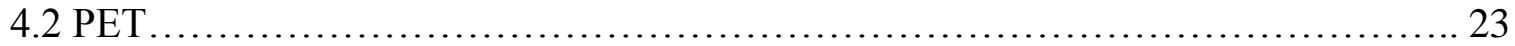

4.3 Soil Moisture..........................................................27

CHAPTER 5 MODEL ANALYSIS ................................................... 34

CHAPTER 6 CONCLUSIONS ................................................... 43

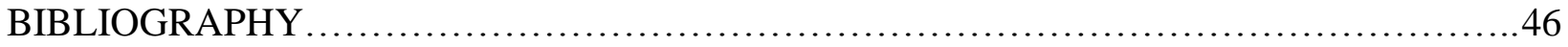




\section{LIST OF TABLES}

Table 1. List of acronymnsandassociated descriptions for all locations described in the study....9

Table 2. Averaged soil texture and estimated soil hydraulic characteristics $\left(K_{s}\right.$ and $\left.\gamma\right)$ for SFS open locations (SO), underneath SFS mountain mahogany shrubs (SM), at NFS forest intercanopy locations (NI), and underneath the NFS ponderosa pine canopy (NP).....10 


\section{LIST OF FIGURES}

Figure 1. Map and aerial photos of the study area with the clusters of instrumentation noted on the south-facing slope (SFS) and north-facing slope (NFS) $\ldots \ldots \ldots \ldots \ldots \ldots \ldots \ldots . \ldots$

Figure 2. Molarity of ethanol droplet (MED) penetrating the soil surface within $10 \mathrm{~s}$ for each sample (points) and average MED at each location (columns) for SO1, NI1, SM1, SP1, NM1, and NP1. Gravimetric water contents are 3\% (SO1), 9\% (NI1), 7\% (SM1), 7\% (SP1), 11\% (NM1), and 8\% (NP1) .................................. 11

Figure 3. Relative locations of plants and instrumentation on the (a) SFS and (b) NFS, and TDR probe placement under (c) mountain mahogany and (d) ponderosa pine. Probes under those plants are oriented parallel and perpendicular to the topographic slope. Diagrams are not to scale.

Figure 4. Hourly throughfall rates (a) at the NFS intercanopy (NI2) location, (b) under the SFS mountain mahogany shrub (SM2), (c) under the NFS mountain mahogany shrub (NM2), and (d) under the NFS ponderosa pine (NP2) plotted against hourly rainfall rates at the SFS open $(\mathrm{SO} 2)$ location.

Figure 5. (a) Average and (b) coefficient of variation of hourly throughfall rates during storms at the SFS open (SO2), NFS intercanopy (NI2), SFS mountain mahogany (SM2), NFS mountain mahogany (NM2), and NFS ponderosa pine (NP2) locations 20

Figure 6. Hourly PET rates (a) at the NFS intercanopy (NI2), (b) under the SFS mountain mahogany SFS (SM2), (c) under the NFS mountain mahogany (NM2), and (d) under the NFS ponderosa pine (NP2) plotted against PET rates at the SFS open (SO2) location. .25 
Figure 7. (a) Average and (b) coefficient of variation of hourly PET rates at the SFS open (SO2), NFS intercanopy (NI2), SFS mountain mahogany (SM2), NFS mountain mahogany (NM2), and NFS ponderosa pine (NP2) locations

Figure 8. Soil moisture (a) at the east NFS intercanopy location (NI3), (b) at the west NFS intercanopy location (NI4), (c) under the SFS mountain mahogany (SM3), (d) under the NFS mountain mahogany (NM3), (e) under the SFS ponderosa pine (SP2), and (f) under the NFS ponderosa pine (NP2) plotted against soil moisture at the SFS shrub intercanopy (SO3) location

Figure 9. (a) Average and (b) coefficient of variation of soil moisture at the SFS intercanopy (SO3), east NFS intercanopy (NI3), west NFS intercanopy (NI4), SFS mountain mahogany (SM3), SFS ponderosa pine (SP2), NFS mountain mahogany (NM3), and NFS ponderosa pine (NP2). For locations having more than one soil moisture probe (under vegetation), the average and coefficient of variation were averaged for all samples. Error bars show the standard deviation of the average and coefficient of variation under each plant

Figure 10. Calibrated values for (a) $\tau$ using the nonlinear ET model, (b) $\tau$ using the linear ET model, (c) $\beta$ using the nonlinear ET model, and (d) $\eta$ using the linear ET model at the SFS intercanopy (SO3) location, east NFS intercanopy (NI3), west NFS intercanopy (NI4), SFS mountain mahogany (SM3), SFS ponderosa pine (SP2), NFS mountain mahogany (NM3), and NFS ponderosa pine (NP2) locations. Where more than one location was simulated (under vegetation), the columns show the average parameter values, and the error bars show the spatial standard deviation of the calibrated parameter values. 


\section{CHAPTER 1 INTRODUCTION}

Soil moisture plays an integral role in many ecohydrologic processes and applications. The portions of rainfall that become infiltration and runoff, for example, are largely determined by soil moisture (Dunne and Black, 1970). Impacts of soil moisture on evapotranspiration (ET) and the surface energy fluxes also affect regional weather and climate (Entekhabi, 1995; Koster et al., 2004). Competition within plant communities for resources such as soil moisture can significantly impact their composition and structure (Lauenroth et al., 1993; D'Odorico et al., 2007; Segoli et al., 2012). Soil moisture also affects soil processes, such as the development of calcium carbonate horizons (Gutierrez-Jurado et al., 2006). Due to these influences and many others, applications involving soil moisture are abundant and include weather forecasting, flood forecasting, agricultural production, and watershed and land management.

The presence of vegetation has an important influence on many components of the soil water balance. During rainfall events, plants alter the quantity and spatial distribution of infiltration by redistributing rainfall into canopy storage, stemflow, and throughfall. The amount of water lost to interception and partitioned into stemflow can vary significantly due to plant species and structure as well as season of the year (Helvey, 1971; Levia and Frost, 2003; Gerrits et al., 2010). In a Sitka Spruce (Picea sitchensis (Bong.) Carr.) plantation, Ford and Deans (1978) observed throughfall patterns with the highest throughfall amounts close to the tree trunk for rainfall amounts between 20 and $40 \mathrm{~mm} / \mathrm{wk}$ (throughfall patterns were less distinct outside this range). However, in a Norway Spruce (Picea abies (L.) Karst.) forest, Beier et al. (1993) found that throughfall was greatest away from the trunk potentially due to the translocation of water by downward-sloping branches and thinner canopy cover away from the trunk. Similarly, Voigt (1960) found soil moisture to be higher near the drip line during rainfall due to thinner 
canopy cover and canopy drip, but Pressland (1976) found no distinct soil moisture patterns traceable to throughfall. In shrubland ecosystems, wind direction has been shown to exert a substantial influence on the distribution of throughfall. In particular, the leeward side of shrubs can experience less throughfall than the windward side (Katra et al., 2008). Voigt (1960), Pressland (1976), and others (Levia and Frost, 2003; Sansoulet et al., 2008; Li et al., 2013) have shown that stemflow can contribute considerably to soil moisture near the plant base, and it is instrumental in storing water at greater soil depths. On hillslopes, stemflow effects can be localized to the downslope side of vegetation bases (Liang et al., 2007). Vegetation patches can also obstruct and retain surface runoff from upslope intercanopy areas. Ludwig et al. (2005), for example, documented that the soils of vegetation patches in semiarid savannas, woodlands, and shrublands contain more water than intercanopy patches because of their ability to obstruct and retain surface runoff.

The presence of vegetation can also influence soil infiltrability. Studies have found higher infiltrability for subcanopy soils due to many factors including the protection of the soil surface by leaf litter, enhanced aggregation of soil particles, and more developed macropore networks (Dunkerley, 2000; Wilcox et al., 2003). Owing to these effects, the magnitude of infiltration and soil moisture has been shown to be higher under vegetation than intercanopy areas under certain conditions (Bhark and Small, 2003). This may not be true for all contexts, however. Moran et al. (2010) found that infiltration and soil moisture are not significantly different between canopy and intercanopy locations except at depths of 15 and $30 \mathrm{~cm}$ where lower soil moisture under vegetation was attributed to root water uptake. Caldwell et al. (2008) found the saturated hydraulic conductivity of soils under shrub canopies in the Mojave Desert to be lower than in intercanopy areas. Decomposing plant material can induce soil water repellency 
and influence spatial patterns of infiltration as well (Doerr et al., 2000; Buczko and Bens, 2006). While water on a hydrophilic surface spreads into a continuous film, water on a hydrophobic surface beads up into individual droplets, which inhibits infiltration. Dekker and Ritsema (2000) demonstrated that rain which falls on water repellent sand does not penetrate evenly but infiltrates through narrow channels, leaving the soil between these channels dry and causing considerable spatial variation in the moisture content. In certain contexts, the spatial variability of soil water repellency has been shown to be related to the proximity to the plant base, where repellency decreases with distance from the stem (Keizer et al., 2005).

Processes involving outflows from the soil, such as ET, are also substantially affected by the presence of vegetation. While roots remove water from the soil at greater depths to supply transpiration, vegetation canopies simultaneously shade the soil surface and reduce soil evaporation (Breshears et al., 1998). In addition to the canopy, organic matter resting above the soil surface can also reduce evaporation (Murphy et al., 2004). Potts et al. (2010) examined the temporal dynamics of soil moisture under and between velvet mesquite (Prosopis velutina Woot.) trees at several depths. In shallow layers, the frequency of extremely dry conditions was reduced relative to bare soil, likely because of the ability of the canopy to shade the soil surface and reduce soil evaporation. At greater depths, however, the frequency distribution of soil moisture was shifted to significantly lower values under the canopy because the root systems deplete soil moisture at these depths. Roots, however, not only deplete soil moisture but also can increase it via hydraulic redistribution, where water is reallocated to drier soil layers during the nighttime (Brooks et al., 2002). Such behavior has been shown to stimulate diurnal fluctuations in soil moisture (Amenu and Kumar, 2008). 
As this brief review demonstrates, many studies have examined the multifaceted effects of vegetation on soil moisture. However, relatively few studies have focused on semiarid environments and even fewer concentrate on the dynamics of shallow $(0-5 \mathrm{~cm}$ depth) soil moisture, which are expected to differ from those of deeper layers. Most rainfall events are small in semiarid climates, so they might only wet the top few centimeters of the soil. This moisture is then depleted rapidly by soil evaporation (Kurc and Small, 2004; Cavanaugh et al., 2011), which has been shown to be restricted to the top $10 \mathrm{~cm}$ of the soil in certain semiarid ecosystems (Newman et al., 1997).

To understand how the presence of trees impacts shallow soil moisture in dryland ecosystems, D'Odorico et al. (2007) examined differences between canopy and intercanopy soil moisture under a variety of tree species and climates associated with different levels of aridity. Their results indicate that shallow soil moisture is typically higher under the canopy than at intercanopy locations and that this contrast increases with increasing levels of aridity. However, the most shallow depth at which soil moisture was measured was at $10 \mathrm{~cm}$, which may be at the fringe of the evaporation front (Newman et al., 1997) and therefore may not exhibit the full effects of evaporation. Potts et al. (2010) studied the effect of velvet mesquite trees in a semiarid savanna on the temporal variation of shallow soil moisture $(2.5-5 \mathrm{~cm})$ and found a reduction in high-frequency variation because the canopy moderates the effects of rainfall and evaporation. Neither D'Odorico et al. (2007) nor Potts et al. (2010) considered spatial variations of soil moisture within areas that are underneath the canopy, which may be important because the effects of vegetation can vary with proximity to the plant base and direction relative to the topographic slope (Voigt, 1960; Keizer et al., 2005; Liang et al., 2007). Pariente (2002) studied how the presence of semiarid shrubs affect shallow soil moisture $(0-10 \mathrm{~cm})$ and found that soil 
moisture decreases with distance from the shrub bases and from the upslope to downslope direction of shrubs. The radial gradient was attributed to higher infiltration rates, overland flow that was captured from intercanopy areas during rainfalls, and lower evaporation rates under the canopy due to shading. The downslope gradient was attributed to the distribution of rock fragments on the hillslope and their effects on infiltration and evaporation. Continuous measurements were not available for this study, which might help detect differences in soil moisture dynamics under different cover types (Bhark and Small, 2003). In addition, similar to both D'Odorico et al. (2007) and Potts et al. (2010), Pariente (2002) compared canopy and intercanopy locations for a given ecosystem. They did not compare the dynamics between different ecosystems in the same climate, which might behave differently.

The objectives of the present study are to characterize the effects of the vegetation on shallow soil moisture dynamics for both forested and shrubland ecosystems in a semiarid montane catchment. In particular, we aim to (1) understand how mountain mahogany (Cercocarpus montanus) and ponderosa pine (Pinus ponderosa) canopies impact throughfall and ET and (2) examine how these effects impact the dynamics of shallow soil moisture. To meet these objectives, observations were collected for soil water repellency, throughfall, insolation, and shallow soil moisture at multiple canopy and intercanopy locations, which are described in Chapter 2 and Chapter 3. Chapter 4 explains statistical analyses that were performed for weather and soil moisture data underneath and between canopies of ponderosa pine and mountain mahogany shrubs in forest and shrubland ecosystems. Chapter 5 describes a simple conceptual model that was used to interpret the differences in soil moisture at each observed location by comparing calibrated parameter values associated with interception and shading. Lastly, the conclusions are summarized in Chapter 6. 


\section{CHAPTER 2 STUDY AREA CHARACTERISTICS}

The study was conducted within a catchment of the Cache la Poudre basin near Rustic, Colorado (latitude $40^{\circ} 41^{\prime} 57^{\prime \prime} \mathrm{N}$, longitude $105^{\circ} 30^{\prime} 25^{\prime}$ ' W: see Figure 1). The area has a semiarid climate with approximately $400 \mathrm{~mm}$ of annual precipitation and $930 \mathrm{~mm}$ of annual potential evapotranspiration (PET) on average (Coleman and Niemann, 2013). Snowfall provides a considerable portion of annual precipitation, averaging about $150 \mathrm{~cm} / \mathrm{yr}$ in depth and occurring mainly between October and May (Arguez et al., 2012). The catchment drains mainly to the east and contains a south-facing slope (SFS) and a north-facing slope (NFS). In total, the catchment is approximately 8 ha with a total relief of $124 \mathrm{~m}$. The study area is included in the Southern Rockies ecoregion (Omernik, 1987) with aspect-dependent vegetation and soils.

The SFS is primarily a shrub/scrub ecosystem (Fry et al., 2011) that contains abundant mountain mahogany and antelope bitterbrush (Purshia tridentate) with a few ponderosa pine and Rocky Mountain juniper (Juniperus scopulorum Sarg.) widely spaced throughout the slope. The mountain mahogany shrubs typically stand between 0.5 and $2.0 \mathrm{~m}$ tall and extend laterally between 0.3 and $1.0 \mathrm{~m}$ between the base and the drip line. Shrubs are spaced sporadically on the slope with denser areas containing intercanopy regions of roughly $0.5 \mathrm{~m}$ and sparser areas providing several meter distances between shrubs. Individual ponderosa pine trees on the SFS generally contain more limbs lower on the trunk than those on the NFS and thus tend to extend wider laterally near the base and have denser canopy cover. Cacti and herbaceous vegetation are also scattered on the SFS. Previous measurements of litter depths on a $15 \mathrm{~m}$ grid at the catchment indicate that litter on the SFS is about $2 \mathrm{~cm}$ deep on average (Lehman and Niemann, 2013).

The NFS is an evergreen forest ecosystem (Fry et al., 2011) consisting mainly of ponderosa pine with scattered Douglas fir (Pseudotsuga menziesii (Mirb.) Franco), Rocky 


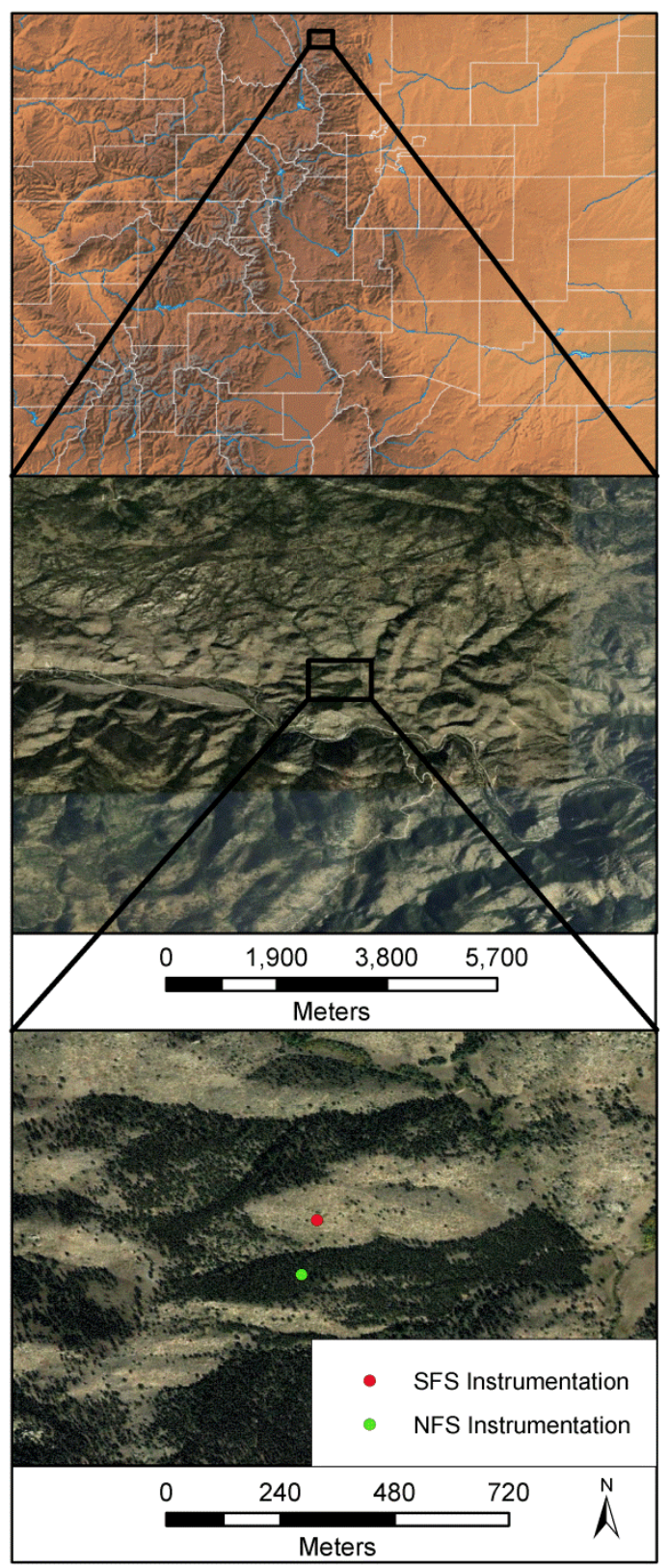

Figure 1. Map and aerial photos of the study area with the clusters of instrumentation noted on the south-facing slope (SFS) and north-facing slope (NFS)

Mountain juniper, and common juniper (Juniperus communus L.). Mountain mahogany and antelope bitterbrush are also distributed throughout the slope. They occur as understory but are found mainly in open areas and near ridges. Mountain mahogany shrubs on the NFS have similar sizes to those on the SFS. Most pine trees on the NFS are roughly $10 \mathrm{~m}$ tall with a diameter at 
breast height (DBH) of about $20 \mathrm{~cm}$, but a small number of larger trees stand a few meters taller and have trunks reaching a DBH of about $40 \mathrm{~cm}$. Minimal herbaceous vegetation exists on this slope. Measurements of litter depth on the NFS suggest that it averages about $4 \mathrm{~cm}$ (Lehman and Niemann, 2013).

Previous analyses of soil samples that were collected on a $30 \mathrm{~m}$ grid at the catchment (Lehman and Niemann, 2013) show that soils on both slopes are mostly sandy loam with a few areas interspersed on both slopes that contain either higher sand content (loamy sand) or higher clay content (sandy clay loam). Larger rocks are prevalent in soils throughout the catchment. Differences in soil texture exist between NFS and SFS, with the NFS having higher silt contents than the SFS. Furthermore, there is more organic matter on the soil surface of the forested portions of the catchment and therefore potentially higher organic content in their shallow soils.

For the present analysis, soil samples were collected and analyzed using the same procedures as Lehman and Niemann (2013) at four types of locations: SFS shrubland intercanopy locations (called SO to denote a south-facing open site), underneath SFS mountain mahogany shrubs (called SM), at NFS forest intercanopy locations (NI), and underneath NFS ponderosa pines (NP). Table 1 lists the acronyms and associated meanings of all locations described in this paper. Six samples were analyzed for SO, six samples were analyzed for SM, three samples were analyzed for NI, and four samples were analyzed for NP. Table 2 shows the average percent sand, silt, and clay for these four location types. While the differences are small, silt is more abundant at the NI and NP locations than the SO and SM locations, which is consistent with the results of Lehman and Niemann (2013). In addition, for both hillslopes, silt is more abundant under the vegetation than at the open or intercanopy locations. This result 
Table 1. List of acronyms and associated descriptions for all locations described in the study

\begin{tabular}{|c|l|}
\hline $\begin{array}{c}\text { Location } \\
\text { Acronym }\end{array}$ & \multicolumn{1}{|c|}{ Location Description } \\
\hline SO & South-facing open locations where soil samples were collected \\
SO1 & South-facing open location where MED tests were performed \\
SO2 & South-facing open location where combo unit is located \\
SO3 & South-facing open location where soil moisture probe is located \\
SM & South-facing mountain mahogany locations where soil samples were collected \\
SM1 & South-facing mountain mahogany location where MED tests were performed \\
SM2 & South-facing mountain mahogany location where combo unit is located \\
SM3 & South-facing mountain mahogany location soil moisture probes are located \\
SP1 & South-facing ponderosa pine location where MED tests were performed \\
SP2 & South-facing ponderosa pine location where soil moisture probes are located \\
NI & North-facing intercanopy locations where soil samples were collected \\
NI1 & North-facing intercanopy location where MED tests were performed \\
NI2 & North-facing intercanopy location where combo unit is located \\
NI3 & North-facing intercanopy location where east soil moisture probe is located \\
NI4 & North-facing intercanopy location where west soil moisture probe is located \\
NM1 & North-facing mountain mahogany location where MED tests were performed \\
NM2 & North-facing mountain mahogany location where combo unit is located \\
NM3 & North-facing mountain mahogany location where soil moisture probes are located \\
NP & North-facing ponderosa pine locations where soil samples were collected \\
NP1 & North-facing ponderosa pine location where MED tests were performed \\
NP2 & North-facing ponderosa pine location where combo unit and soil moisture probes \\
\end{tabular}

suggests that the reason silt is more abundant on the NFS is the abundance of vegetation on that hillslope.

Soil water repellency has been found under semiarid vegetation and is known to impact moisture dynamics (Dekker and Ritsema, 2000; Buczko and Bens, 2006), so tests were performed to investigate the severity of soil water repellency at the catchment. The Molarity of Ethanol Droplet (MED) test was used to assess surface water repellency (Roy and McGill, 2002). This test indirectly measures the surface tension of a soil by iteratively placing drops with varying concentrations of ethanol onto the soil until droplet entry is observed within 10 s. For this study, solutions were prepared using tap water and a denatured ethanol source (containing 90-100\% ethanol and $\leq 10 \%$ methanol, methyl isobutyl ketone, and ethyl ester as denaturing 
Table 2. Averaged soil texture and estimated soil hydraulic characteristics $\left(K_{s}\right.$ and $\left.\gamma\right)$ for SFS open locations (SO), underneath SFS mountain mahogany shrubs (SM), at NFS forest intercanopy locations (NI), and underneath the NFS ponderosa pine canopy (NP)

\begin{tabular}{|c|c|c|c|c|c|}
\hline Location Type & Sand (\%) (+ $/)$ & Silt $(\%)(+/)$ & Clay $(\%)(+/)$ & $K_{s}(\mathrm{~mm} / \mathrm{hr})$ & $\gamma$ \\
\hline SO & $68.5(7.0)$ & $20.7(3.9)$ & $10.8(4.1)$ & 39.6 & 12.2 \\
SM & $66.7(1.4)$ & $23.1(1.0)$ & $10.2(0.9)$ & 38.0 & 12.0 \\
NI & $66.4(2.1)$ & $25.3(2.1)$ & $8.3(2.9)$ & 38.8 & 11.4 \\
NP & $62.8(3.2)$ & $27.1(2.3)$ & $10.1(1.0)$ & 33.9 & 12.0 \\
\hline
\end{tabular}

agents) in increments of $0.2 \mathrm{M}$ up to a $6 \mathrm{M}$ concentration. Droplets were placed on the soil surface (litter was removed, if present) at six location types. On the SFS, the location types were intercanopy (SO1), under a mountain mahogany (SM1), and under a ponderosa pine (SP1). On the NFS, the locations were intercanopy (NI1), under a mountain mahogany (NM1), and under a ponderosa pine (NP1). One test each was performed at SO1 and NI1, and eight tests were performed for each vegetation type (SM1, SP1, NM1, and NP1). Tests were performed in May 2013 during a relatively dry period. Because soil water repellency depends on soil moisture, the gravimetric water content was determined for each sample and ranged from $3 \%$ to $11 \%$. After testing, the results were referenced to qualitative scales that rate MED results in terms of the severity of water repellency (King, 1981).

Figure 2 shows the MED results. For location types where repellency was tested at more than one site (under vegetation), the shaded columns show the average value for each location type, while the results of each test are plotted as points. MED values at the open and intercanopy locations (SO1 and NI1) indicate that no measurable soil water repellency is present. This result is consistent with Schnabel et al. (2013) who found that areas not covered by organic matter are hydrophilic. Additionally, all average values under vegetation are considered low ( $\leq 1.0 \mathrm{MED})$ according to King (1981). Of all the samples under vegetation, only a few were considered to 
have moderate (1.2-2.2 MED: 3 samples) or severe (2.4-3.0 MED: 2 samples) soil water repellency and were not associated with any clear spatial pattern surrounding the plant base. Average MED values are larger for soils under ponderosa pine than soils under mountain mahogany on their respective slopes. This result may be due to differences in the amount of litter that accumulates under each plant type or differences in the wax in the litter (Verheijen and Cammeraat, 2007; Schnabel et al., 2013). In addition, average MED values are larger for the NFS than the SFS, which is likely due to the thicker organic layer that occurs on the NFS. MED tests were repeated in the laboratory following Roy and McGill (2002) and water repellencies fell in a similar range as in the field. Thus, soil water repellency is expected to be low in general and only impact soil moisture at a few localized points under vegetation.

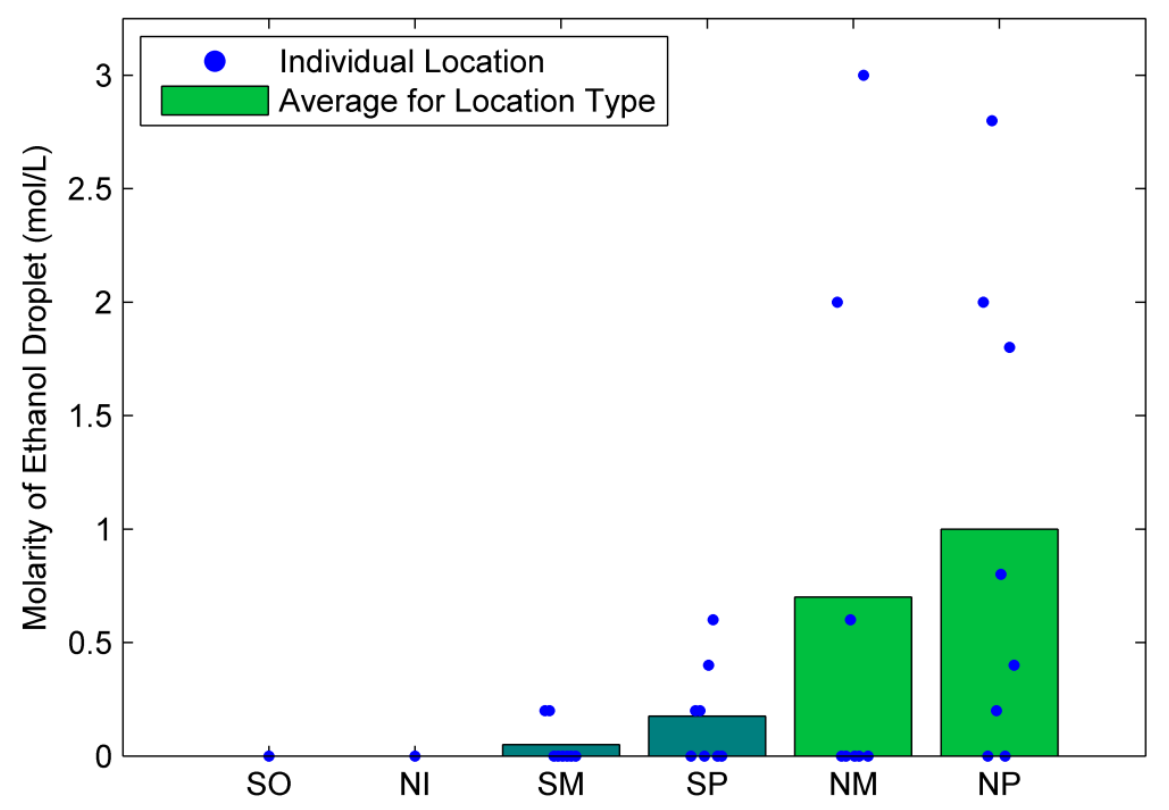

Figure 2. Molarity of ethanol droplet (MED) penetrating the soil surface within $10 \mathrm{~s}$ for each sample (points) and average MED at each location (columns) for SO1, NI1, SM1, SP1, NM1, and NP1. Gravimetric water contents are 3\% (SO1), 9\% (NI1), 7\% (SM1), 7\% (SP1), $11 \%$ (NM1), and $8 \%$ (NP1) 


\section{CHAPTER 3 FIELD INSTRUMENTATION}

Extensive instrumentation was installed in the catchment to analyze how the presence of mountain mahogany and ponderosa pine affects shallow soil moisture. The measurements were collected for three years between April 2011 and August 2013, but the two winter periods were excluded (October 2011 to April 2012 and November 2012 to May 2013) to avoid the effects of snowpack and frozen soil. In addition, one period of data from early August to mid-September 2011 was not collected due to equipment failure.

Much of the instrumentation was focused on estimating the PET and throughfall for the various location types on the NFS and SFS. Figure 1 shows where the instrumentation is clustered on each hillslope, while Figures $3 a$ and $3 b$ provide schematic diagrams of the instrumentation included in each cluster. To estimate PET, measurements were collected for temperature, humidity, and insolation. Temperature and humidity were measured only at a single site on each hillslope (labeled as weather stations in Figure 3). These sensors measure the average ambient air temperature and relative humidity every half-hour. Wind speed is also measured at the weather stations but is not used in this paper. On the NFS, insolation is measured with pyranometers for an intercanopy location (NI2), under a mountain mahogany shrub (NM2), and under a pine tree (NP2). On the SFS, insolation is measured for an open location (SO2) and under a mountain mahogany shrub (SM2). Insolation is not measured under a ponderosa pine tree on the SFS due to practical constraints. The pyranometers measure the incoming solar radiation plus diffuse sky radiation (300 to $1100 \mathrm{~nm}$ wavelengths), reported as the total flux density for half-hour intervals. Throughfall is measured at the same locations as insolation (labeled as "combo units" in Figure 3) using six-inch diameter tipping-bucket rain gauges that record values every half-hour by summing the number of tips in each time interval 


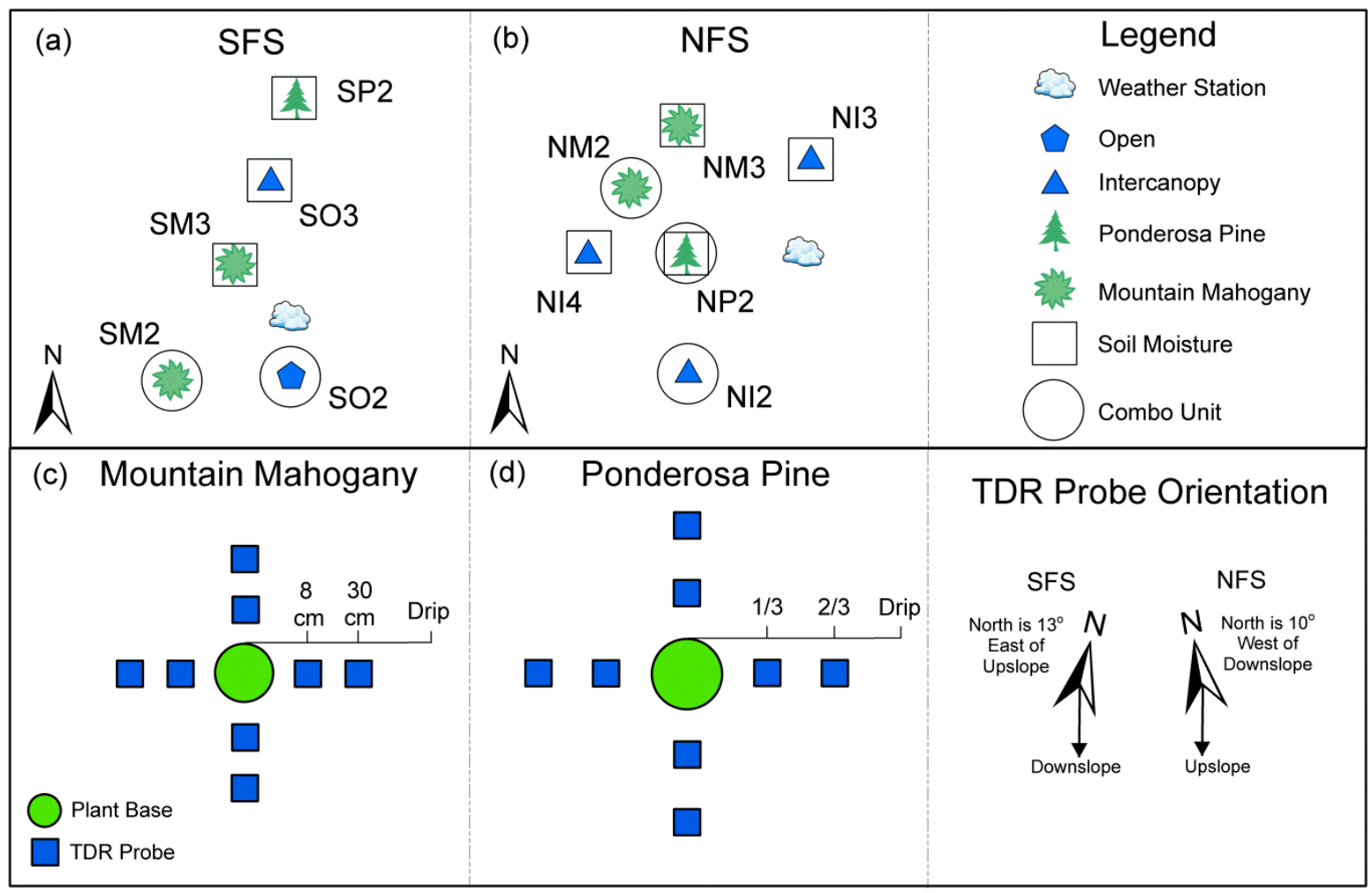

Figure 3. Relative locations of plants and instrumentation on the (a) SFS and (b) NFS, and TDR probe placement under (c) mountain mahogany and (d) ponderosa pine. Probes under those plants are oriented parallel and perpendicular to the topographic slope. Diagrams are not to scale

and multiplying by the depth per tip $(0.254 \mathrm{~mm})$. The manufacturer's calibration of the rain gages was verified in the field.

Details regarding the instrument positioning with respect to the plant dimensions are as follows. The combo unit at NI2 was placed as far from surrounding trees as possible (about 1.2 $\mathrm{m}$ away from the nearest drip line). It is mounted well below the tree tops, which is why it is considered an intercanopy site. The unit at NM2 is positioned less than $10 \mathrm{~cm}$ from the downslope side of the plant base. The plant at NM2 stands about $1.3 \mathrm{~m}$ tall with a distance of approximately $50 \mathrm{~cm}$ between the base and the drip line. The unit under NP2 is located approximately $35 \mathrm{~cm}$ northeast of the downslope side of the trunk. The tree at NP2 extends to 
roughly $10 \mathrm{~m}$ tall with a DBH of about $20 \mathrm{~cm}$ and a distance of approximately $1.5 \mathrm{~m}$ between the trunk and the drip line. The unit at $\mathrm{SO} 2$ is placed as far from the nearest shrubs as possible and above the height of the surrounding shrubs $(1 \mathrm{~m})$, so it is considered an open site rather than an intercanopy site. The combo unit at SM2 is positioned about $20 \mathrm{~cm}$ downslope from the plant base. The plant itself stands about $1.5 \mathrm{~m}$ tall with a distance of approximately $70 \mathrm{~cm}$ between the base and the drip line. It appears to have denser canopy cover than the shrub at NM2.

Shallow soil moisture $(0-5 \mathrm{~cm})$ is measured at the same types of locations. On the NFS, soil moisture is measured at two intercanopy locations (NI3 and NI4), under a mountain mahogany shrub (NM3), and under a pine tree (NP2). The probes at NI3 and NI4 are positioned as far away from surrounding trees as possible (roughly $70 \mathrm{~cm}$ from the closest tree canopy). On the SFS, soil moisture is measured at an open location (SO3), under a mountain mahogany (SM3), and under a ponderosa pine (SP2). The probe at SO3 is located as far from surrounding shrubs as possible with a distance of roughly $40 \mathrm{~cm}$ to the nearest shrub canopy. Soil moisture is monitored under an under antelope bitterbrush, but those measurements are not used in this paper. Soil moisture is also monitored at an additional open location on the SFS, but after installation, the site was determined to be too close to a drip line to be representative of open conditions.

For all soil moisture sites under vegetation, multiple probes were installed as shown in Figures $3 \mathrm{c}$ and $3 \mathrm{~d}$. For NM3 and SM3, the probes are located 8 and $30 \mathrm{~cm}$ from the plant base underneath the canopy. The plant at NM3 extends to roughly $1.5 \mathrm{~m}$ tall and has a distance of about $65 \mathrm{~cm}$ between the base and the drip line. The plant at SM3 also stands roughly $1.5 \mathrm{~m}$ tall and has a distance of about $70 \mathrm{~cm}$ between the base and the drip line. For NP2 and SP2, the probes are located at $1 / 3$ and $2 / 3$ of the distance to the drip line (plant characteristics are given 
earlier). In all cases, the probes are positioned to radiate from the plant base both parallel and perpendicular to the topographic gradient.

At each site, soil moisture is measured using time-domain reflectometry (TDR). The waveforms are generated by Campbell Scientific TDR100s, and the probes are Campbell Scientific CS635 models with tines that were originally $15 \mathrm{~cm}$ long but were shortened to $5 \mathrm{~cm}$. These probes were selected and modified because the tines have a larger diameter than the available probes with shorter lengths, which makes them more durable for the rocky conditions at the catchment. The probes are inserted vertically from the ground surface.

Soil moisture measurements are taken at an hourly interval, and winters are excluded to avoid the effects of snowpack and frozen soil. To determine frozen soil conditions, soil temperature probes were installed near soil moisture probes. Winter periods are identified as beginning at the first persistent occurrence of soil temperatures lower than $0^{\circ} \mathrm{C}$ and ending 20 days following the last persistent occurrence of soil temperatures lower than $0^{\circ} \mathrm{C}$ to allow for snowmelt.

The first season of waveforms (April to October 2011) was interpreted using the proprietary Campbell Scientific algorithm, but this algorithm had problems correctly interpreting low values of soil moisture. These problems likely occurred in part due to the relatively long cable lengths that were necessary at the catchment (up to $7.5 \mathrm{~m}$ ) (Noborio 2001). After the first season, the TACQ algorithm (Evett, 2000) was used instead, but the first season was not reprocessed with TACQ because no waveforms were retained for that period. The TACQ algorithm reduced the problems but did not remove them completely.

Calibration equations were developed to relate the apparent dielectric permittivity (obtained from waveform interpretation) to volumetric soil moisture following the procedure 
given by Evett et al. (2008). Because soil moisture measurements were taken using two different waveform interpretation algorithms, a separate calibration equation was developed for each algorithm. Also, because measurements were taken on hillslopes with some differences in their soil properties, a separate calibration equation was developed for each hillslope (giving a total of four calibration equations). To develop each calibration equation, the apparent dielectric permittivity of three relatively wet samples $\left(>0.25 \mathrm{~m}^{3} / \mathrm{m}^{3}\right)$ and three relatively dry samples $(<$ $0.15 \mathrm{~m}^{3} / \mathrm{m}^{3}$ ) was measured using TDR probes at the field site and then compared to volumetric soil moisture determined from gravimetric measurements in lab. The volumetric soil moisture was then plotted against the square-root of the apparent dielectric permittivity, and the calibration equations were found from linear regressions. The calibration equations on the SFS are $y=0.10 x-0.12\left(r^{2}=0.99\right)$ for Campbell Scientific and $y=0.11 x-0.07\left(r^{2}=0.99\right)$ for TACQ where $y$ is volumetric soil moisture and $x$ is the square-root of the apparent dielectric permittivity. On the NFS, the calibrations equations are $y=0.10 x-0.09\left(r^{2}=0.99\right)$ for Campbell Scientific and $y=0.11 x-0.10\left(r^{2}=1.00\right)$ for TACQ.

The TDR soil moisture data were then processed to identify and remove the errors that occurred under dry conditions. The errors are easily identifiable. When the soil moisture dries to about $0.05 \mathrm{~m}^{3} / \mathrm{m}^{3}$, the reported values sometimes rapidly increase to very large values without rainfall occurring. The large values may persist until the actual soil moisture exceeds $0.05 \mathrm{~m}^{3} / \mathrm{m}^{3}$ again in response to a rainfall event. Due to the nature of the errors, the actual values of soil moisture are known to fall within a narrow range $\left(<0.05 \mathrm{~m}^{3} / \mathrm{m}^{3}\right)$. In addition, because the errors consistently occur at low soil moisture values, discarding them would bias statistics like averages. Consequently, the incorrect values were removed from the dataset and replaced by linearly interpolating between the last preceding and next following reliable values or by 
substituting the last reliable data value if the next reliable value is influenced by precipitation. The average percent of interpolated data amongst all probes for the entire period of data collection was $12 \%$ on the SFS and $13 \%$ on the NFS. Additionally, one period of data for the inner west lateral probe at SP2 was removed due to the probe being partially exposed above the soil between July and October 2012. 


\section{CHAPTER 4 RESULTS}

\subsection{Throughfall}

To investigate differences in the throughfall received at the different location types, hourly throughfall rates at the north-facing intercanopy location (NI2), under mountain mahogany shrubs on both hillslopes (SM2 and NM2), and under the NFS ponderosa pine (NP2) were plotted against hourly rainfall rates in the open (SO2) (Figure 4). Periods where no precipitation was recorded at any of the gages were excluded from the analysis. Throughfall under vegetation sometimes occurs in the plots when the rainfall in the open is zero. Such points usually occur when throughfall is delayed relative to the rainfall. If throughfall is a constant fraction of rainfall, a clear linear relationship would occur between throughfall at a given location type and the rainfall at $\mathrm{SO} 2$. In all plots, however, considerable scatter occurs, which suggests that throughfall depends on other variables such as the intensity of rainfall, wind direction, and season (Ford and Deans, 1978; Beier et al., 1993). Linear regressions were performed (with intercepts that are forced to be zero) and are shown in the plots. For the forest intercanopy location (NI2), the slope of the linear regression suggests that throughfall is about $58 \%$ of the rainfall at SO2. Under the mountain mahogany shrubs (SM2 and NM2), the slopes indicate that throughfall is roughly between 31\% (SM2) and 44\% (NM2) of rainfall. NM2 likely has higher throughfall than SM2 because it has noticeably sparser canopy cover. Because mountain mahogany shrubs are deciduous, seasonal differences in interception also occur under both SM2 and NM2. Although not shown in the figure, this effect is evident because the throughfall rates are more similar to the rainfall rates near the beginning and end of the season when canopy cover is reduced. Under the ponderosa pine (NP2), the slope suggests that throughfall is roughly $41 \%$ of rainfall. In all cases, however, the linear regressions have 

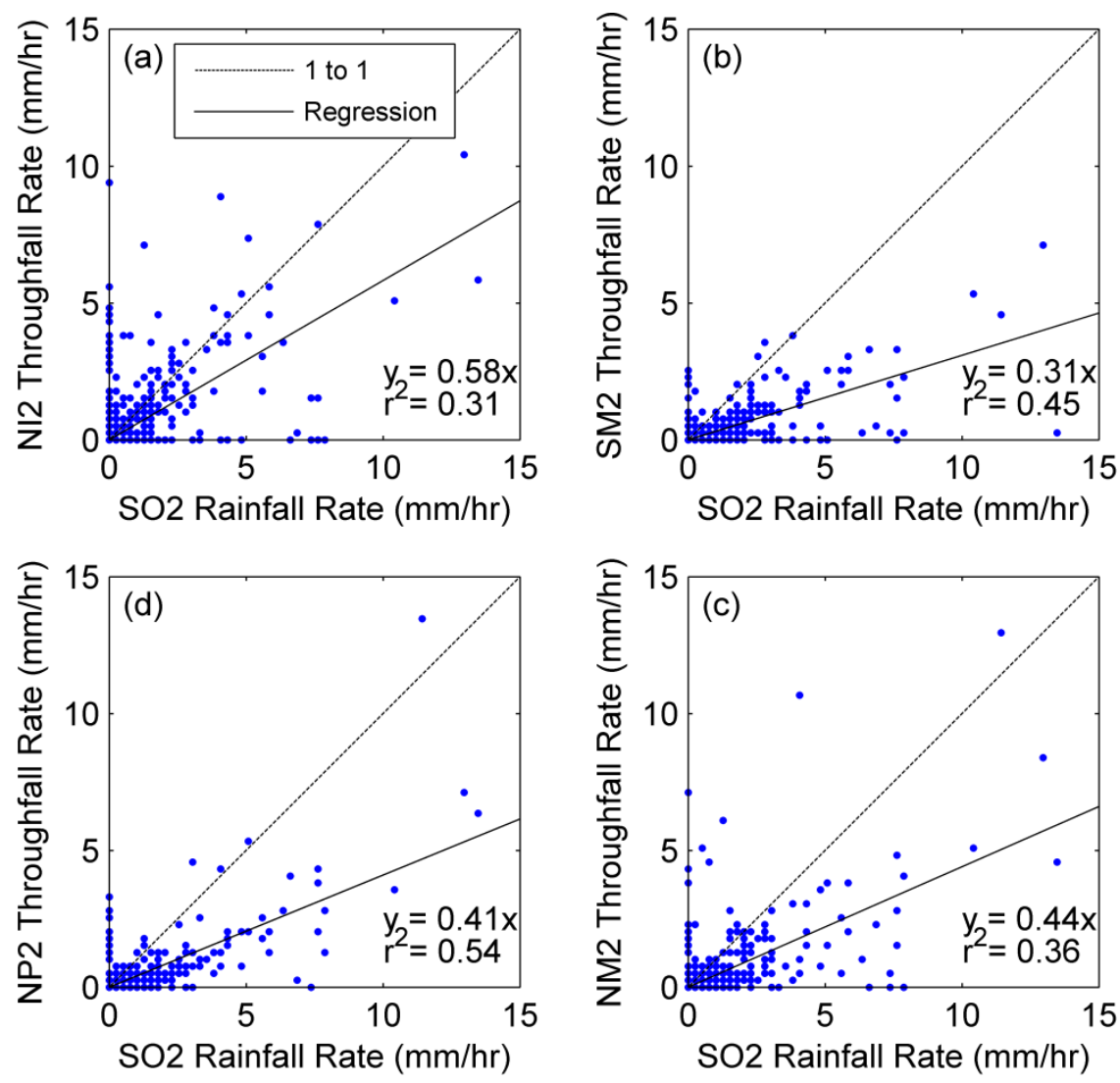

Figure 4. Hourly throughfall rates (a) at the NFS intercanopy (NI2) location, (b) under the SFS mountain mahogany shrub (SM2), (c) under the NFS mountain mahogany shrub (NM2), and (d) under the NFS ponderosa pine (NP2) plotted against hourly rainfall rates at the SFS open (SO2) location

relatively low coefficients of determination $\left(r^{2}\right)$, so the throughfall fraction varies widely between different time periods.

Figure 5a examines the differences in the throughfall rates by directly plotting the average throughfall rate for each location when rainfall occurs. It is important to note that the averages are a function of the rainfall rates that were observed during the study period and whether rainfall was observed at the other gages (in which case zero values are included). Thus, they are meaningful primarily for comparison between the locations. The average rainfall at SO2 $(0.73 \mathrm{~mm} / \mathrm{hr})$ is similar to the average throughfall at NI2 $(0.66 \mathrm{~mm} / \mathrm{hr})$. It is interesting that the ratio of these values (0.90) is so large when the linear regression between these locations 
produced a slope of 0.58 . The apparent inconsistency occurs due to differences in the analysis methods, which can be illustrated by considering the case where throughfall only delays the flow
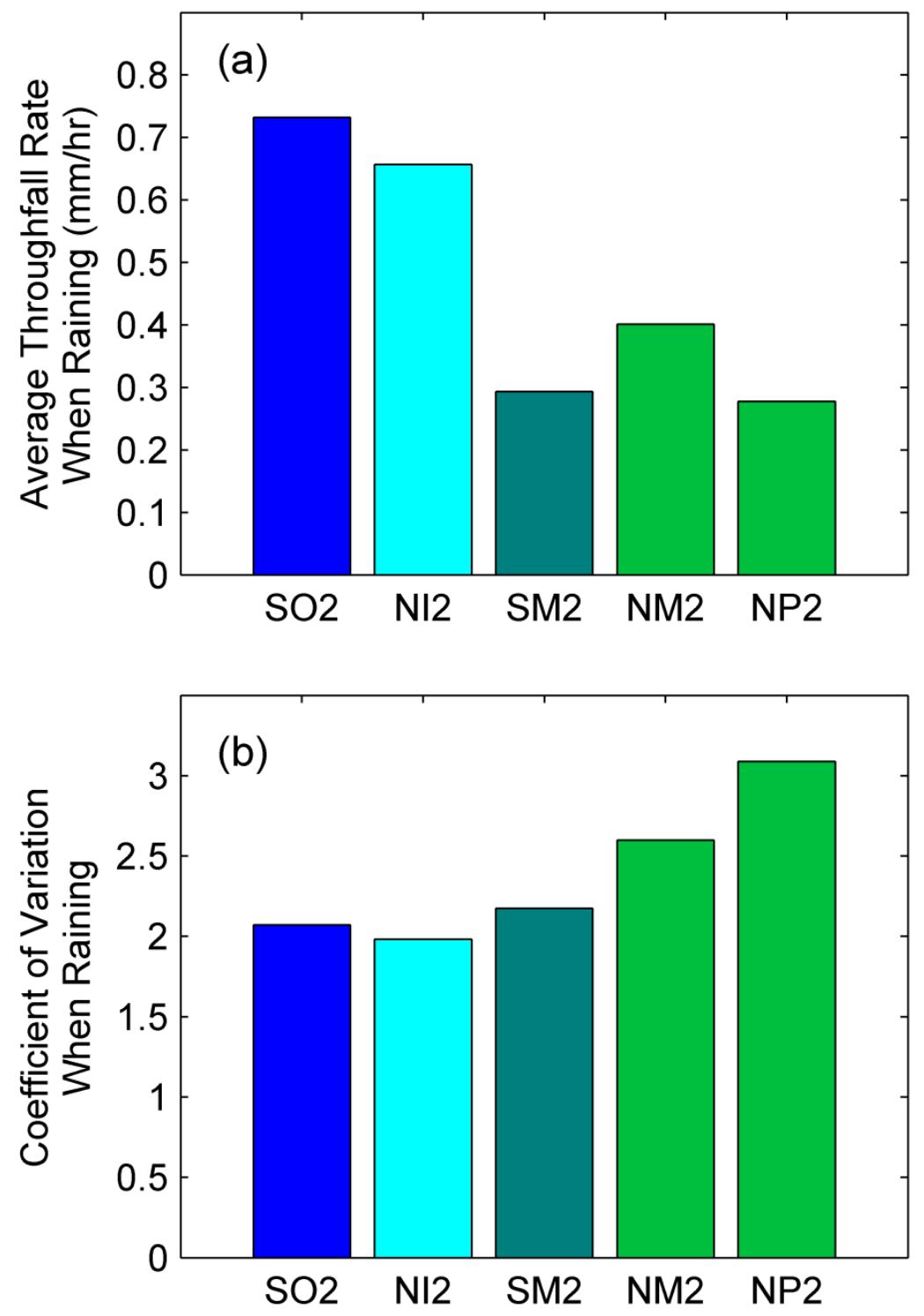

Figure 5. (a) Average and (b) coefficient of variation of hourly throughfall rates during storms at the SFS open (SO2), NFS intercanopy (NI2), SFS mountain mahogany (SM2), NFS mountain mahogany (NM2), and NFS ponderosa pine (NP2) locations

of water into the rain gage rather than reducing it. In that case, the average throughfall rate would match the average rainfall at $\mathrm{SO} 2$ rate because the total depth and number of time periods are the same in both cases. However, the regression slope would be less than one. Figure 5 also 
shows that the average throughfall under mountain mahogany shrubs (SM2 $=0.29 ; \mathrm{NM} 2=0.40$ ) and ponderosa pine $(\mathrm{NP} 2=0.28)$ are much lower than $\mathrm{SO} 2$. These results are more consistent with the regressions presented in the previous figure.

The Wilcoxon rank-sum test (Beaumont and Knowles, 1996) was used to quantify the probability $(P)$ that differences in throughfall between locations are only due to random sampling variation (LeBlanc, 2004). Specifically, the Wilcoxon test evaluates the null hypothesis that the two populations have the same distribution by analyzing the rankings of the data values in the two samples when they are combined into a single dataset. Because the test considers the rankings of the data values rather than the actual values, it is more robust with respect to deviations from normality than tests for differences in the mean (such as the t-test). The test does, however, require that samples are independent (LeBlanc, 2004). It is possible that throughfall rates are correlated in time, so the correlogram (which gives the autocorrelation coefficient between observations of the same sample at different lags) was determined for each location. If a time series is completely independent, then the autocorrelation coefficient for $95 \%$ of the lags beyond zero will fall within $\pm 1.96 / \sqrt{ } N$ where $N$ is the total number of observations in a given sample (Chatfield, 1996). This condition holds for all rain gauge data at the catchment, so independence is a reasonable assumption and the test can be used. The Wilcoxon test indicates that differences between NI2 and SO2 are more likely due to random sampling variation $(P=$ 0.66) than significant interception. However, recall that the regression slope in Figure 4 indicates a greater difference between $\mathrm{NI} 2$ and $\mathrm{SO} 2$ than the averages shown here. The Wilcoxon test indicates low probabilities $(P<0.05)$ that differences between rainfall in the open (SO2) and throughfall under both plant types are due to random sampling variation. Thus, both vegetation types intercept significant rainfall. Additionally, the tests suggest that differences 
between throughfall under mountain mahogany shrubs (SM2 and NM2) and ponderosa pine (NP2) are not likely due to random sampling variation $(P<0.05)$.

Differences in the temporal variability of throughfall were analyzed by comparing the coefficient of variation at each location when rainfall occurs (Figure 5b). The coefficient of variation is similar for the rainfall in the open (SO2) and the throughfall at the forest intercanopy (NI2). The coefficient of variation for throughfall under the SFS mountain mahogany (SM2) is also similar to SO2, but the coefficient of variation is noticeably higher under NM2 and NP2. If throughfall is a simple portion of incoming rainfall, then the coefficient of variation is expected to be the same under vegetation as in the open (because both the mean and the standard deviation will be reduced). However, the fact that throughfall under NM2 and NP2 has a higher coefficient of variation suggests that the presence of the canopy not only reduces the amount of water reaching the surface but also adds variability in that amount. This variability could occur if a location is shielded for some wind directions but not from others, for example due to the position the plant base relative to the rain gage or variations of the canopy structure. The rain gauge is relatively close to the trunk at NP2, which likely contributes to the higher variability in that case.

Statistical tests are not available to directly evaluate whether differences in the coefficient of variation are statistically significant. However, one can define new variables by dividing the throughfall rates by their sample averages. The standard deviations of the new variables are equal to the coefficients of variation of the throughfall rates. Then, one can apply tests that evaluate whether the differences in the variance of the new variables are statistically significant. The Levene test (LeBlanc, 2004) was used, which evaluates the null hypothesis that the average absolute deviation of the observation from the sample average is the same between two samples 
(LeBlanc, 2004). While there is no completely satisfactory test for comparing measures of spread between non-normal samples, the Levene test is less sensitive to non-normal distributions than other tests such as the F-test (LeBlanc, 2004). Results from the Levene test indicate relatively high probability that differences between the coefficients of variation for SO2 and NI2 $(P=0.74)$ and $\mathrm{SO} 2$ and SM2 $(P=0.74)$ are due to random sampling variation, but lower probability that differences between the coefficient of variation for SO2 and NM2 $(P=0.23)$ and $\mathrm{SO} 2$ and NP2 $(P=0.14)$ are due to random sampling variation. The difference between the coefficient of variation for SM2 and NP2 is unlikely to be due to random sampling variation $(P=0.19)$, but the difference between NM2 and NP2 is associated with a higher probability $(P=0.48)$.

\subsection{PET}

To assess the effects of shading by the shrubs and trees on evaporation from the shallow soil, PET rates were calculated for each location type using the Priestley-Taylor method (Priestley and Taylor, 1972). The Penman-Monteith (Allen et al., 1998) method was considered but not chosen for several reasons. Most notably, it requires vegetation information in its equation, so it would produce differences in the PET values for the different locations in advance of any field measurements. Thus, the Priestley-Taylor method was used to allow a more consistent comparison between sites. The Priestley-Taylor method assumes that radiation data are collected by level instrumentation and calculates the PET for a horizontal surface. The insolation data used for the PET calculations are the values recorded by the pyranometers at the different location types. Thus, the calculated values describe the PET under the canopy if present at the site. The insolation data at the various location types are collected by level pyranometers, but the locations all have sloping surfaces. To account for the slopes, the observed radiation data were multiplied by the potential solar radiation index (PSRI), which is the ratio of 
the insolation of the sloped surface relative to that of a horizontal surface at the same time and location. It depends on the topographic aspect and slope as well as the angle and position of the sun relative to the surface, which changes with the day of the year (Dingman, 2002). Coleman and Niemann (2013) calculated the slope and aspect on a 15 by $15 \mathrm{~m}$ grid throughout the catchment. We used the values nearest to the instrumentation on each slope to calculate the PSRI for this analysis.

Figure 6 shows the hourly PET rates at the forest intercanopy (NI2), the SFS mountain mahogany (SM2), the NFS mountain mahogany (NM2), and the NFS ponderosa pine (NP2) locations plotted against hourly PET rates at the SFS open location (SO2). The figure also shows linear regressions that were fitted to the observations (with intercepts that are forced to be zero). PET rates at NI2 are lower than those at $\mathrm{SO}$, and the regression slope indicates that NI2 PET is generally about $22 \%$ of that in the open. Similar to NI2, PET rates under both NM2 and NP2 are lower than at SO2, and the regression slopes indicate that PET is generally reduced to $22 \%$ of the PET at SO2 at both locations. PET under SM2 is also usually lower than the PET at $\mathrm{SO} 2$, but it is higher than all of the NFS sites (35\% based on the regression slope). The lower values of PET for NI2, NM2, and NP2 are due to both shading by the canopy and the orientation of the hillslope away from the sun (i.e. lower PSRI values). However, the mean relative error between PET rates calculated with and without PSRI is only 10\% (averaged for all locations), suggesting that shading is the primary cause of the reduction in PET. Some of the scatter in the plots is related to changes in the sun angle between different times of day and different times of year. On the SFS, PET rates under the mountain mahogany shrub are most similar to SO2 during periods of the year when leaf cover is minimal and the angle of the sun is low (at the beginning and end of the season considered). At low sun angles, the radiation is more likely to pass through 

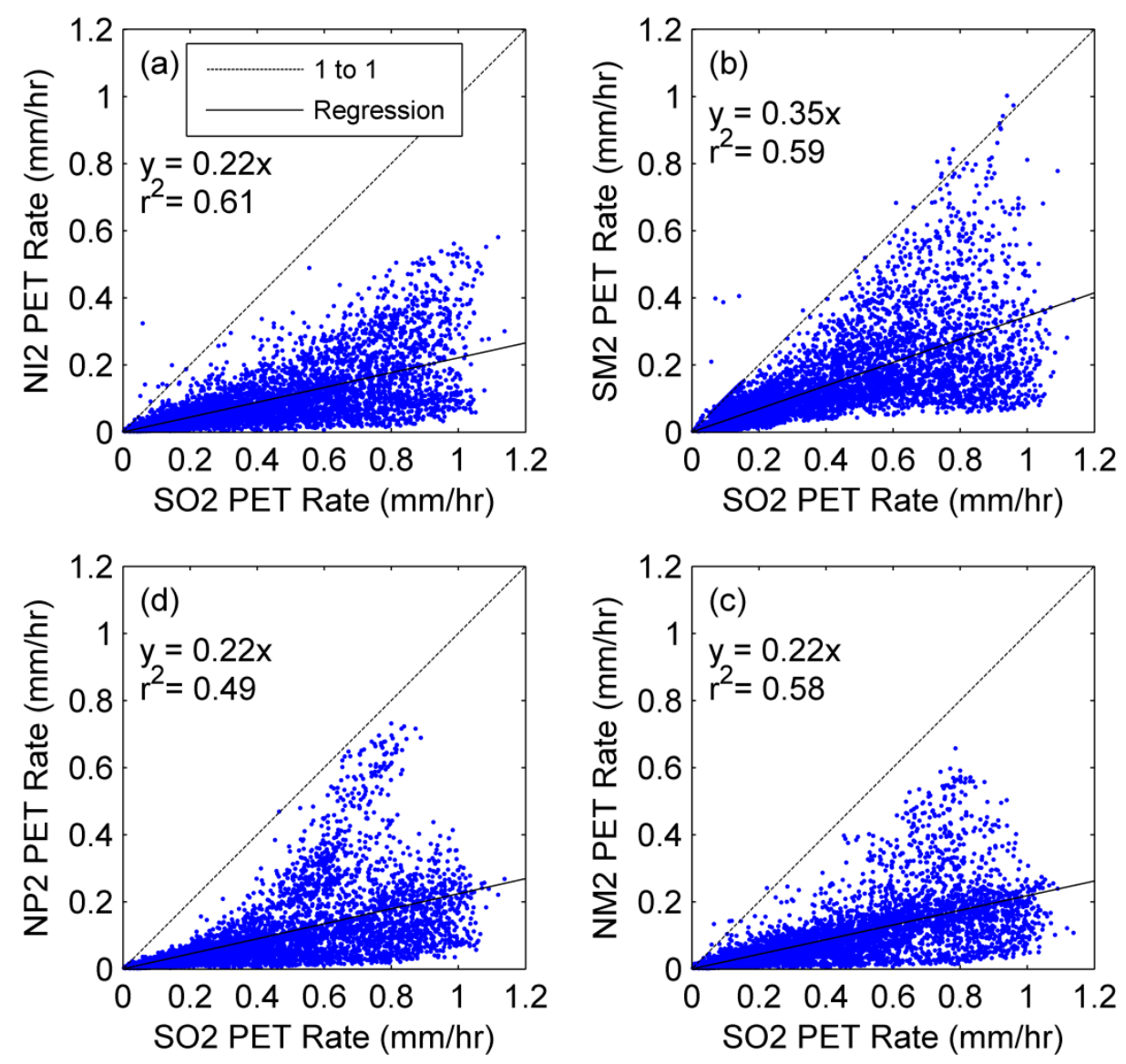

Figure 6. Hourly PET rates (a) at the NFS intercanopy (NI2), (b) under the SFS mountain mahogany SFS (SM2), (c) under the NFS mountain mahogany (NM2), and (d) under the NFS ponderosa pine (NP2) plotted against PET rates at the SFS open (SO2) location

open sections of the SFS. In contrast, on the NFS, the PET values are most similar to SO2 near the summer solstice when the angle of the sun is highest. Due to the taller and denser canopy on this hillslope, higher sun angles tend to reduce the canopy cover that the radiation encounters. These periods are especially noticeable in the split that occurs for SO2 PET rates higher than about $0.50 \mathrm{~mm} / \mathrm{hr}$ in Figures $6 \mathrm{c}$ and $6 \mathrm{~d}$.

Figure 7a shows the average hourly PET rate (including both day and night) for each location. The average PET at NI2 $(0.05 \mathrm{~mm} / \mathrm{hr})$ is much lower than the average PET at SO2 $(0.25 \mathrm{~mm} / \mathrm{hr})$, which is consistent with the results of the regressions in Figure 6. The average 

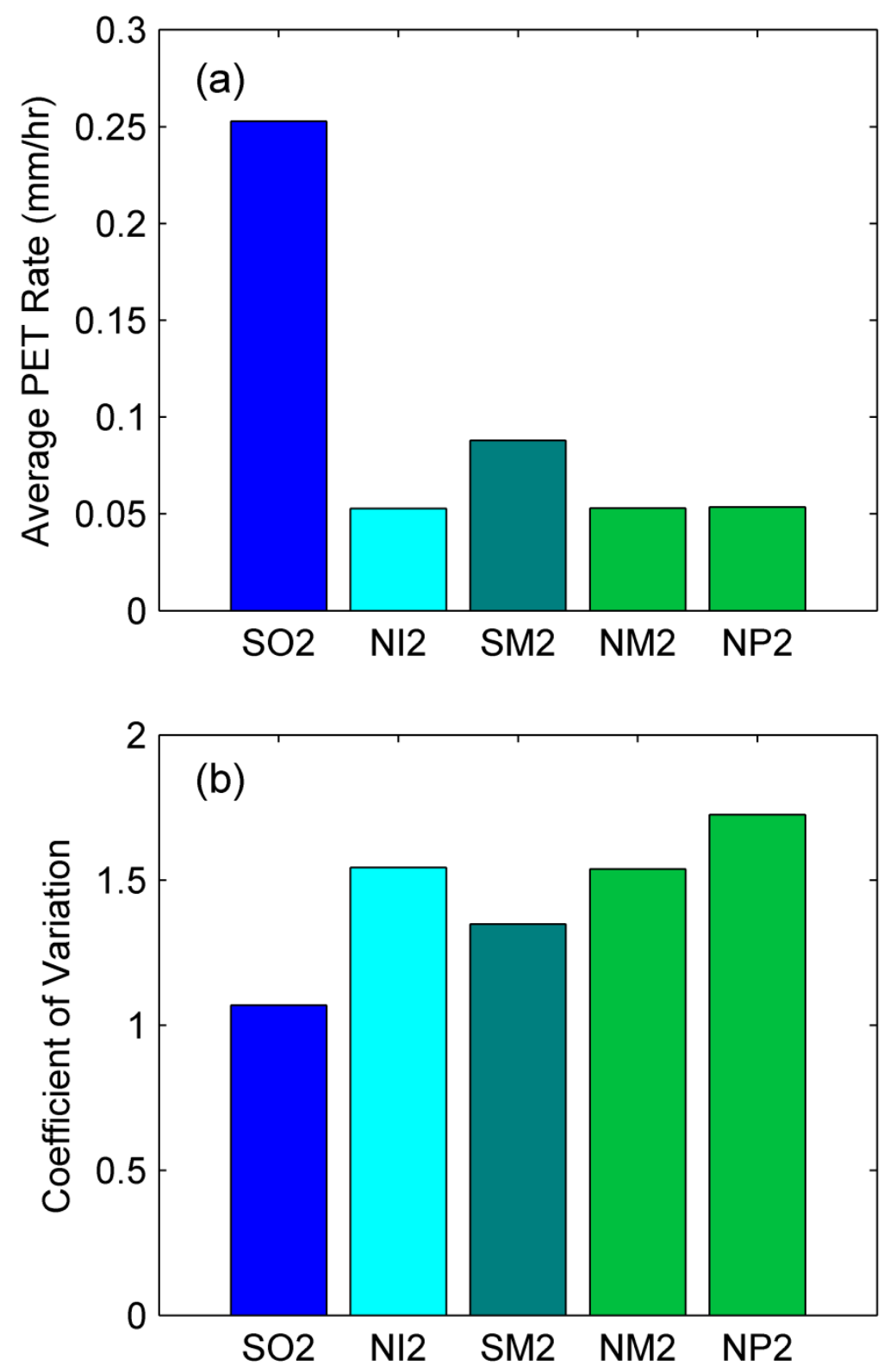

Figure 7. (a) Average and (b) coefficient of variation of hourly PET rates at the SFS open (SO2), NFS intercanopy (NI2), SFS mountain mahogany (SM2), NFS mountain mahogany (NM2), and NFS ponderosa pine (NP2) locations

PET rates at both NM2 and NP2 are nearly identical to that at NI2. This similarity suggests that the shading at a particular location on the NFS does not depend strongly on the canopy that is directly above the location (which differs between the NFS locations). Instead, it depends on the canopy that shades the location from all the relevant sun positions throughout the day and 
year (which is likely similar among the NFS locations). The average PET under SM2 (0.09 $\mathrm{mm} / \mathrm{hr}$ ) is also less than half of $\mathrm{SO} 2$ but larger than all locations on the NFS, which is also consistent with regression slopes. Tests for significance were not applied to the average PET because the PET data have significant autocorrelation for long periods of time and therefore violate one of the primary assumptions of the Wilcoxon test.

Figure $7 \mathrm{~b}$ shows the coefficient of variation for the PET rates at each observed location. The highest coefficients of variation occur for the NFS locations (NI2, NM2, and NP2). Thus, the canopy not only reduces PET at these sites but also adds variability due to fluctuations in shading during different times of the day and year. NP2 has the highest coefficient of variation, which may be due to the placement of the pyranometer near the trunk (causing longer periods of shading at certain angles of the sun). The coefficient of variation under SM2 is also higher than at $\mathrm{SO} 2$ but lower than locations on the NFS. This lower value is expected because the site also experiences less shading on average. Due to the autocorrelation in the PET data, the Levene test was not applied.

\subsection{Soil Moisture}

To examine the dynamics of shallow soil moisture under and between vegetation, soil moisture at forest intercanopy locations (NI3 and NI4), under mountain mahogany (SM3 and NM3), and under ponderosa pine (SP2 and NP2) are plotted against the soil moisture at the SFS open location (SO3) in Figure 8. The plotted soil moisture values under vegetation are the average of the observations from all TDR probes under each plant. In all plots, distinct bands of points are visible, which are associated with drying periods following rainfall events. For both NFS intercanopy sites NI3 and NI4, the soil is usually wetter than at SO3 during dry conditions $\left(<0.10 \mathrm{~m}^{3} / \mathrm{m}^{3}\right.$ at SO3). This result may occur because the NFS intercanopy consistently receives 
much less insolation than the SFS open site as observed earlier. Thus, ET is expected to be lower during inter-storm periods, which would help maintain higher soil moisture values under dry conditions at the NFS intercanopy sites. For wet conditions $\left(>0.10 \mathrm{~m}^{3} / \mathrm{m}^{3}\right.$ at SO3), distinct behaviors are observed for NI3 and NI4. While the soil at NI3 is usually wetter than the soil at SO3, the soil at NI4 is usually drier than SO3 for wet conditions. Earlier results showed that throughfall is a little lower at the NFS intercanopy than in the SFS open, but the magnitude of the reduction was inconsistent between the analysis methods. Here, the behavior of the soil moisture at NI3 suggests it receives nearly the same throughfall as the SFS open location, which helps maintain the wetter conditions. In contrast, the drier conditions at NI4 suggest that some interception might be occurring from the surrounding canopy at this soil moisture probe. Considering the mountain mahogany, the soil under SM3 is usually wetter during dry conditions due to shading, but can be both wetter and drier than at SO3 during wet conditions. The diversity of behavior for wet conditions may be due seasonal differences in interception associated with varying leaf cover. The soil under NM3 is wetter during dry conditions (again, likely due to shading effects) but is generally drier during wet conditions (likely due to interception). NM3 might behave differently from SM3 because this location is also affected by the surrounding ponderosa pine canopy, which can produce interception when the deciduous leaves are absent. Soil moisture under both SP2 and NP2 generally follows a pattern that is similar to NM3, where the soil under the canopy is wetter during dry conditions and drier during wet conditions (in comparison to the open location). The combined effect of these tendencies is to reduce the range of variation in soil moisture under both plant types. The reduced range is confirmed in the extreme values of soil moisture. While the lowest values of soil moisture in the open approach zero, the lowest values under vegetation range between 0.02 and $0.03 \mathrm{~m}^{3} / \mathrm{m}^{3}$. The 

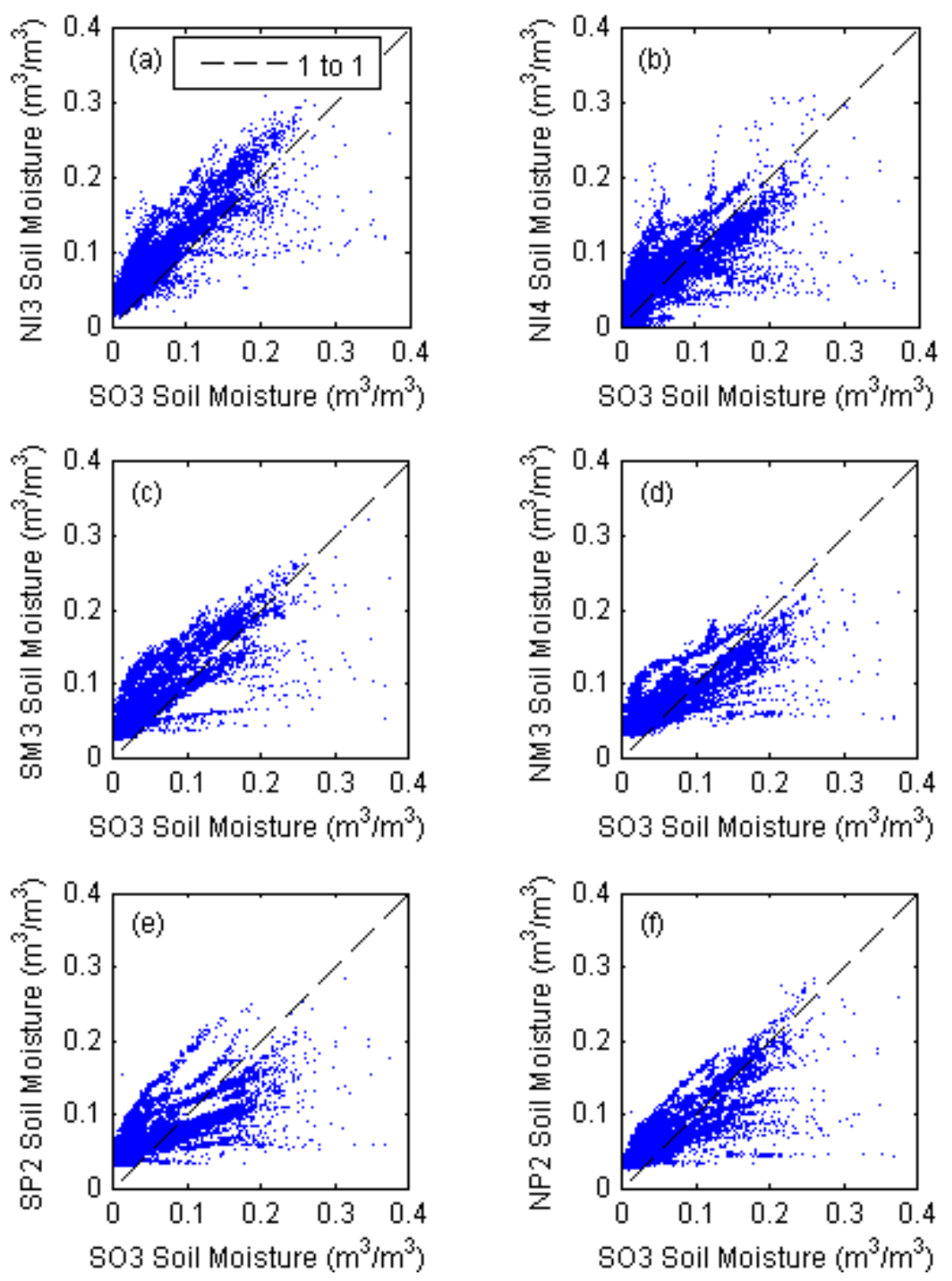

Figure 8. Soil moisture (a) at the east NFS intercanopy location (NI3), (b) at the west NFS intercanopy location (NI4), (c) under the SFS mountain mahogany (SM3), (d) under the NFS mountain mahogany (NM3), (e) under the SFS ponderosa pine (SP2), and (f) under the NFS ponderosa pine (NP2) plotted against soil moisture at the SFS shrub intercanopy (SO3) location

highest values of soil moisture for the open site reach nearly $0.40 \mathrm{~m}^{3} / \mathrm{m}^{3}$, but the highest values under vegetation only reaches about $0.30 \mathrm{~m}^{3} / \mathrm{m}^{3}$.

The net effects of shading and interception can be seen in the average soil moisture at each observed location (Figure 9a). For locations where data were collected from more than one 
TDR probe (under vegetation), the value that is displayed is the average of the averages for each probe. The error bars show the spatial standard deviation of the averages for each probe. The average soil moisture at the SFS open location (SO3) is the driest amongst all observed locations. The average soil moisture value at one NFS intercanopy location (NI3) is much higher than SO3, while the average at the other such location (NI4) is nearly identical to SO3. The relatively wet conditions at NI3 are consistent with earlier results that showed this site is consistently wetter than SO3. The similarity in the averages of NI4 and SO3 are also expected because NI4 is wetter than $\mathrm{SO} 3$ under dry conditions and drier than $\mathrm{SO} 3$ under wet conditions. The average soil moisture under all vegetation types (SM3, SP2, NM3, and NP2) is higher than SO3. Thus, the effect that shading has in increasing the soil moisture is on average stronger than the effect that interception has in reducing the soil moisture for the conditions considered.

The Wilcoxon test was used to estimate the probability that differences in the soil moisture between locations are due only to random sampling variation. Because hourly soil moisture observations are not independent, the tests were performed by considering soil moisture values from a subset of times that are each separated by 17 days. This length of time was found to be sufficient to produce independent observations. At locations where data were collected from more than one TDR probe (under vegetation), observations from all probes were averaged for each time step to yield one sample for that location type. Wilcoxon tests were performed on the averaged sample. The Wilcoxon tests indicate low probability $(P<0.05)$ that differences between the soil moisture at the SFS open site (SO3) and all other locations except NI4 ( $P=$ 0.31 ) are due to random sampling variation. Thus, the wetter conditions that are observed under the vegetation are statistically significant. Additionally, the tests indicate low probabilities that 

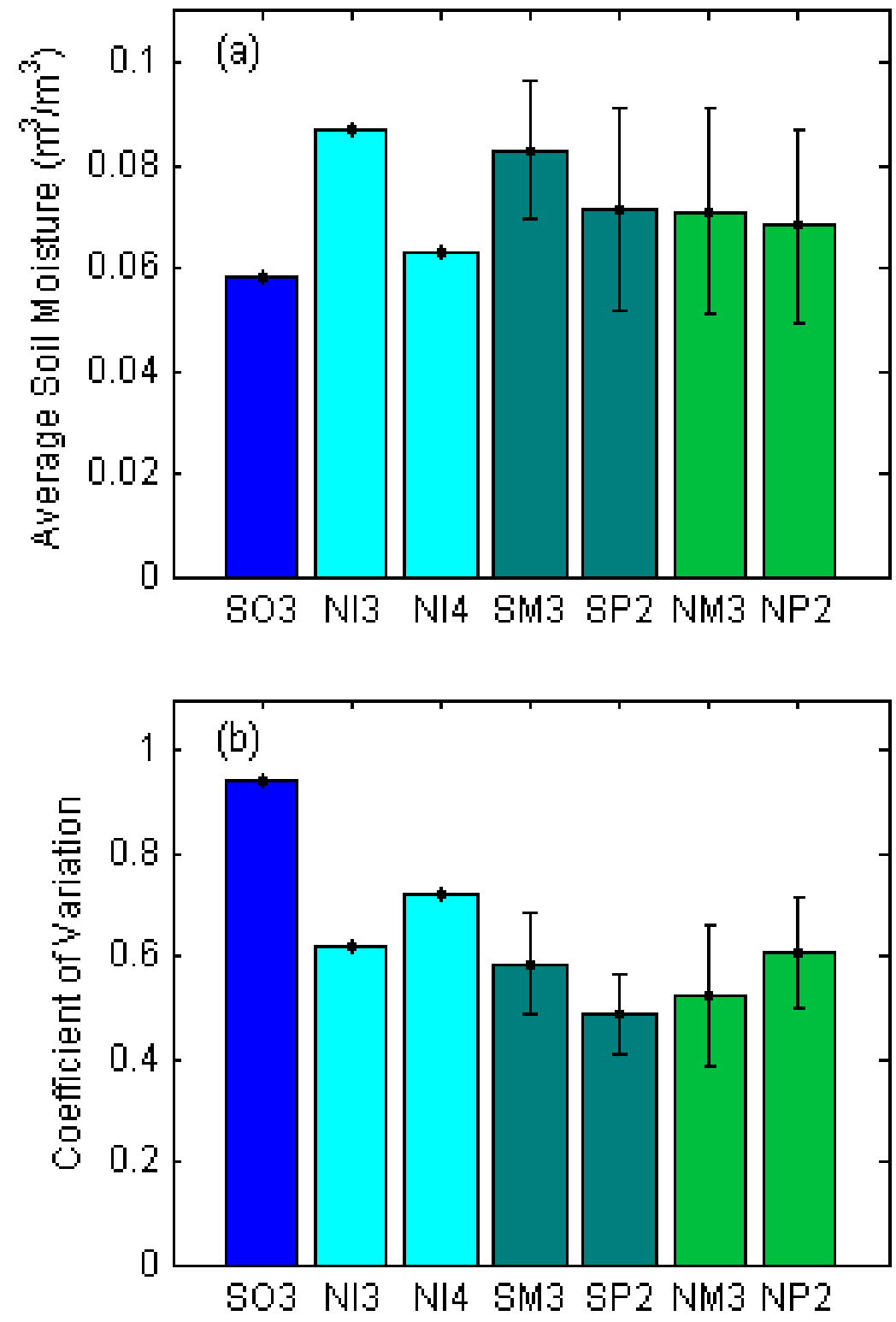

Figure 9. (a) Average and (b) coefficient of variation of soil moisture at the SFS intercanopy (SO3), east NFS intercanopy (NI3), west NFS intercanopy (NI4), SFS mountain mahogany (SM3), SFS ponderosa pine (SP2), NFS mountain mahogany (NM3), and NFS ponderosa pine (NP2). For locations having more than one soil moisture probe (under vegetation), the average and coefficient of variation were averaged for all samples. Error bars show the standard deviation of the average and coefficient of variation under each plant

the differences between NI3 and NI4 $(P<0.05)$ and NI3 and NP2 $(P=0.08)$ are due to random sampling variation. However, higher probabilities exist between NI3 and SM3 $(P=0.64)$, NI3 
and SP2 $(P=0.27)$, NI3 and NM3 $(P=0.17)$, SM3 and SP2 $(P=0.72)$, and NM3 and NP2 $(P=0.42)$. Thus, differences in the soil moisture of intercanopy, mountain mahogany, and ponderosa pine locations remain uncertain.

Figure $9 \mathrm{~b}$ shows the temporal coefficient of variation for each location. The coefficient of variation at both NFS intercanopy sites (NI3 and NI4) is lower than that at SO3. Similarly, the coefficient of variation for all sites under vegetation (SM3, SP2, NM3, and NP2) is lower than that at SO3. These results are expected from the reduced ranges in soil moisture values that were documented earlier. Nonetheless, it is interesting that the soil moisture is more stable under vegetation even though the throughfall rates and PET rates, which help determine soil moisture, are usually more variable. To assess the significance of the differences in Figure 9b, Levene tests were performed. Similar to the Wilcoxon test, the Levene tests were performed on the spatially-averaged soil moisture sample for location types with multiple TDR probes (under vegetation). The results give relatively low probabilities that differences between SO3 and NI3 $(P=0.06), \mathrm{SO} 3$ and NI4 $(P=0.21), \mathrm{SO} 3$ and SM3 $(P=0.10), \mathrm{SO} 3$ and SP2 $(P<0.05), \mathrm{SO} 3$ and NM3 $(P<0.05)$, and SO3 and NP2 $(P=0.09)$ are due to random sampling variation. The tests give higher probabilities that differences between NI3 and NI4 $(P=0.20)$, NI3 and SM3 $(P=$ $0.55), \mathrm{NI} 3$ and SP2 $(P=0.72), \mathrm{NI} 3$ and NM3 $(P=0.60)$, and NI3 and NP2 $(P=0.74)$ are due to random sampling variation. Tests between plant types also give higher probabilities that differences between SM3 and SP2 $(P=0.37)$ as well as between NM3 and NP2 $(P=0.45)$ are due to random sampling variation. Thus, the results strongly suggest that the vegetated and intercanopy locations have lower coefficients of variation than the open site, but the differences between the intercanopy and different vegetation types are likely due to random sample variations. 
The spatial standard deviation of soil moisture under each plant is shown by the error bars in Figures 9a and 9b. The standard deviations are relatively large (Figure 9a $\sim 0.02$; Figure $9 b \sim 0.10$ ), signifying that there can be considerable differences in soil moisture dynamics under individual plant canopies. To investigate whether proximity to the plant base plays a role, the average and coefficient of variation of soil moisture for the inner locations were compared to those for the outer locations. However, no consistent patterns were found. To investigate whether the position relative to the topographic slope plays a role, the average and coefficient of variation of soil moisture at upslope locations were compared to those calculated for downslope locations under each plant. Although no consistent spatial patterns were found on the SFS, the average soil moisture on the downslope side of the SFS ponderosa pine is much higher than upslope locations, which may be due to stemflow. Conversely, soil moisture on the downslope side of NFS vegetation is lower than soil moisture on the upslope side, similar to results from Pariente (2002) which were attributed to variations in the abundance of rock fragments. In the present case, this difference may be due to the accumulation of litter on the upslope of NFS vegetation (which would reduce insolation on the soil and decrease ET for these locations). 


\section{CHAPTER 5 MODEL ANALYSIS}

In order to understand the connections between the throughfall, PET, and soil moisture observations, a simple conceptual model is applied to simulate the soil moisture records. In this analysis, the parameters associated with interception and shading at each observed location are inferred from the soil moisture observations. The selected model was presented previously by Niemann and Eltahir (2004) and Tripp and Niemann (2008). It simulates local, depth-averaged soil moisture using a simple water balance, given as:

$$
\theta_{t+1}=\theta_{t}+\frac{\Delta t}{\delta}(F-E-G)
$$

where $\theta$ is volumetric soil moisture, which is assumed to be constant within the soil layer being considered, $\Delta t$ is the time step, $\delta$ is the depth of soil layer being considered, $F$ is the infiltration rate, $E$ is the ET rate, and $G$ is the drainage from the base of the soil layer. Although it is possible that lateral flow also influences soil moisture in some cases, it is not included because Coleman and Niemann (2013) showed that this process is not important at the Cache la Poudre catchment.

Infiltration $F$ is determined as the smaller of the soil's infiltration capacity $F_{c}$ and the portion of rainfall that reaches the soil layer and is determined from:

$$
F=\left\{\begin{array}{cc}
F_{c} & \text { If } F_{c}<\tau \sigma P \\
\tau \sigma P & \text { If } F_{c} \geq \tau \sigma P
\end{array}\right.
$$

The infiltration capacity is defined as $F_{c}=\alpha[1-(\theta / \phi)]+K_{s}$ where $\alpha$ is an infiltrability parameter, $\phi$ is the soil porosity, and $K_{s}$ is the saturated hydraulic conductivity. Consequently, $F_{c}=K_{s}$ when the soil is saturated and $F_{c}=\alpha+K_{s}$ when the soil is completely dry. The rainfall 
that reaches the soil layer is $\tau \sigma P$ where $\tau$ represents the proportion of rainfall that reaches the litter cover (i.e. the throughfall fraction), $\sigma$ represents the portion of throughfall that is retained by the litter (where it is assumed to evaporate), and $P$ is the rainfall rate. The inclusion of $\tau$ and $\sigma$ is a modification of Tripp and Niemann (2008), who neglected canopy and litter effects at their open application sites.

ET from the soil layer is modeled using two different approaches. The first approach, which is referred to as the nonlinear ET model, follows Tripp and Niemann (2008) and models ET as a function of PET and water availability. It is given as:

$$
E=E_{p}\left(\frac{\theta}{\phi}\right)^{\beta}
$$

where $E_{p}$ is the PET and $\beta$ is an ET exponent. This expression implies that ET is equal to $E_{p}$ when the soil is saturated and zero when the soil is completely dry. $\beta$ controls the impact of any soil moisture limitation on ET, where lower values correspond to higher ET rates for a given $\theta$. Lowry (1959) summarized the results of several studies examining the relationship between ET and the degree of soil saturation. Put together, the studies find that the relationship is controlled by soil and vegetation characteristics. In a fully vegetated area, the ET remains close to the PET for all soil moisture conditions except for very dry conditions (Pierce, 1958), which is represented by $\beta<1$. Similarly, Entekhabi et al. (1992) set $\beta=0.5$ to represent the presence of vegetation in a sub-humid climate. For soil conditions where root-water uptake is likely not as significant, such as bare soil, soils with deep-rooted crops, or soil covered by mulch of dead vegetation, the ET decreases more rapidly from the PET as the soil moisture decreases (Lowry, 1959), which is represented by $\beta>1$. This ET model does not explicitly account for shading of 
the soil surface. If $E_{p}$ is specified as the PET above the vegetation canopy (i.e. without any shading effects), than any shading effect will be accounted for in the calibrated values of $\beta$.

The second approach, which is referred to as the linear ET model, includes a parameter that can more directly account for shading. It is written:

$$
E=E_{p} \eta\left(\frac{\theta}{\phi}\right)
$$

where $\eta$ is a parameter that represents the portion of the PET that is available to the soil layer. This approach differs from the nonlinear model in two ways. The first difference from the nonlinear model is that the moisture limitation effect is linear $(\beta=1)$, which is an approximation derived from the behavior of this parameter as described earlier. The second difference is the inclusion of $\eta$, which allows more direct consideration of shading. It should be noted that $\eta$ is not equivalent to the fraction of the insolation reaching the ground surface. Shading only affects the insolation, which is embedded in the PET variable. In addition, if roots are present in the modeled soil layer, then some insolation that strikes the canopy can still produce ET from the soil layer.

The rate of drainage $G$ from the soil layer is described by:

$$
G=K_{s}\left(\frac{\theta}{\phi}\right)^{\gamma}
$$

which can be derived by assuming percolation and using the Campbell (Campbell, 1974) equation to describe the unsaturated hydraulic conductivity. In such a case, $\gamma$ is the pore disconnectedness index. $G=K_{s}$ when the soil is saturated, and $G=0$ when the soil is completely dry. 
The model was applied to each location with a TDR probe for the period between April 2012 and November 2012. This season was selected because it contains the most complete soil moisture data. The model requires four characteristics that can be constrained by observations: $\delta, \phi, K_{s}$, and $\gamma$. Because soil moisture observations are taken for the top $5 \mathrm{~cm}$ of the soil, $\delta$ is set to $5 \mathrm{~cm}$. Porosity can be found from $\phi=1-\left(\rho_{b} / \rho_{p}\right)$ where $\rho_{b}$ is the bulk density and $\rho_{p}$ is the particle density. Bulk density was estimated near the instrumentation on each hillslope and found to be $1.48 \mathrm{~g} / \mathrm{cm}^{3}$ for the SFS and $1.40 \mathrm{~g} / \mathrm{cm}^{3}$ for the NFS. Using a commonly-assumed value of $2.65 \mathrm{~g} / \mathrm{cm}^{3}$ for particle density (Jury and Horton, 2004), the porosity can be estimated to be 0.44 for the SFS and 0.47 for the NFS. The saturated hydraulic conductivity and pore disconnectedness index were estimated by using the soil texture data and the multivariate pedotransfer functions developed by Cosby et al. (1984). A possible disadvantage to using those functions is that they do not account for the abundance of very large particle sizes in the soil, which are common at this site. The calculated values for $K_{s}$ and $\gamma$ at all locations (Table 1) are typical for sandy loam (Cosby et al., 1984; Carsel and Parrish, 1988; Dingman, 2002), which is the most prevalent soil type in the catchment. On the SFS, both the saturated hydraulic conductivity and pore disconnectedness index are similar for soil under and between vegetation. Under the NFS forest canopy (NP2), the saturated hydraulic conductivity is slightly lower than the other sites. Because soil texture was only characterized under mountain mahogany (SM) and ponderosa pine (NP2), the hydraulic parameters from those sites were applied to simulate soil moisture under the same plants on both hillslopes. To test this assumption, soil moisture under SP2 was also simulated using the hydraulic characteristics from SM, but this change had little effect on the results. 
Five parameters $(\alpha, \tau, \sigma, \eta$, and $\beta)$ were calibrated to minimize the disagreement between the simulated and observed soil moisture values. In order to allow the calibrated parameters to infer the influence of vegetation from the soil moisture dynamics, the model at all locations was forced with hourly rainfall and PET data from the open location (SO2) and the parameters were allowed to differ for each site. To calibrate the model, 250 initial parameter sets were randomly generated from uniform distributions within the feasible ranges for each parameter. The feasible range for $\alpha$ was taken from Tripp and Niemann (2008), and the feasible range for $\beta$ was taken from Coleman and Niemann (2013) who also used a model with this parameter. The feasible ranges for $\tau, \sigma$, and $\eta$ were chosen to be 0 to 1 , which represents all possible conditions. Because $\tau$ and $\sigma$ have the same mathematical effect in the model, two assumptions are needed to distinguish their roles. First, $\sigma$ is assumed to be the same at all simulated locations. This assumption likely underestimates the effect of litter cover under vegetation because litter cover is likely thicker in those locations. Second, $\tau$ is assumed equal to one at the SFS open location (SO3) because canopy cover is minimal at this location. Under these assumptions, $\sigma$ can be calibrated at $\mathrm{SO} 3$ (where $\tau=1$ ) for each ET formulation and used at all locations. Then, $\tau$ can be calibrated for each remaining location. In all cases, the calibrations are performed by modifying the randomly generated parameter sets to minimize the root mean square error (RMSE) between the simulated and observed soil moisture time series. Other objective functions such as the Nash-Sutcliffe coefficient of efficiency and mean absolute error were considered, but the calibrated parameters are relatively insensitive to the particular objective function used. After calibration at a given location, all initial values of $\sigma, \tau, \eta$, and $\beta$ typically converge to the same final values. In cases where more than one final value is obtained, the value associated with the lowest RMSE is taken. The final value of $\alpha$ does not 
affect the model results because the maximum precipitation rate for the period of simulation $(13.46 \mathrm{~mm} / \mathrm{hr})$ is lower than the saturated hydraulic conductivity at all locations. Using the nonlinear ET model, the values of RMSE among all simulated locations averaged $0.018 \mathrm{~m}^{3} / \mathrm{m}^{3}$ and ranged from 0.010 to $0.031 \mathrm{~m}^{3} / \mathrm{m}^{3}$. Using the linear model, the values of RMSE averaged $0.022 \mathrm{~m} 3 / \mathrm{m} 3$ and ranged from $0.010 \mathrm{~m}^{3} / \mathrm{m}^{3}$ to $0.032 \mathrm{~m}^{3} / \mathrm{m}^{3}$.

The calibrated values for $\sigma$ ( 0.48 for the nonlinear model; 0.51 for the linear model) indicate that a significant portion of rainfall is captured by litter cover and never reaches the soil. The rainfall amounts are generally small during the simulated period, so it is possible that a large portion of the throughfall is lost before reaching the soil layer, but this fraction is higher than expected. It is possible that this loss also includes water that enters macropores and quickly drains to deeper layers (and thus does not appear in the $0-5 \mathrm{~cm}$ soil moisture values). Both the rainfall and soil moisture measurements were verified in the field, so it is unlikely that the difference is due to measurement errors.

The calibrated values of $\tau$ using the nonlinear ET model and the linear ET model are shown in Figure 10a and 10b, respectively. For locations under vegetation where more than one location is simulated, the columns and error bars show the average and standard deviation of the calibrated values, respectively. The values for $\tau$ are very similar between the two modeling approaches. In both methods, the values for $\tau$ at NI3 and NI4 differ substantially from each other. While the values at NI3 ( 0.57 for the nonlinear model; 0.72 for the linear model) are more similar to the regression slope between the throughfall rates at NI2 and SO2 that was presented earlier $(0.58)$, the values at NI4 are lower $(0.27$ for the nonlinear model; 0.24 for the linear model). The lower values suggest that a larger amount of rainfall is being intercepted by the surrounding canopy at NI4 than NI3. Considering the mountain mahogany, the average $\tau$ 

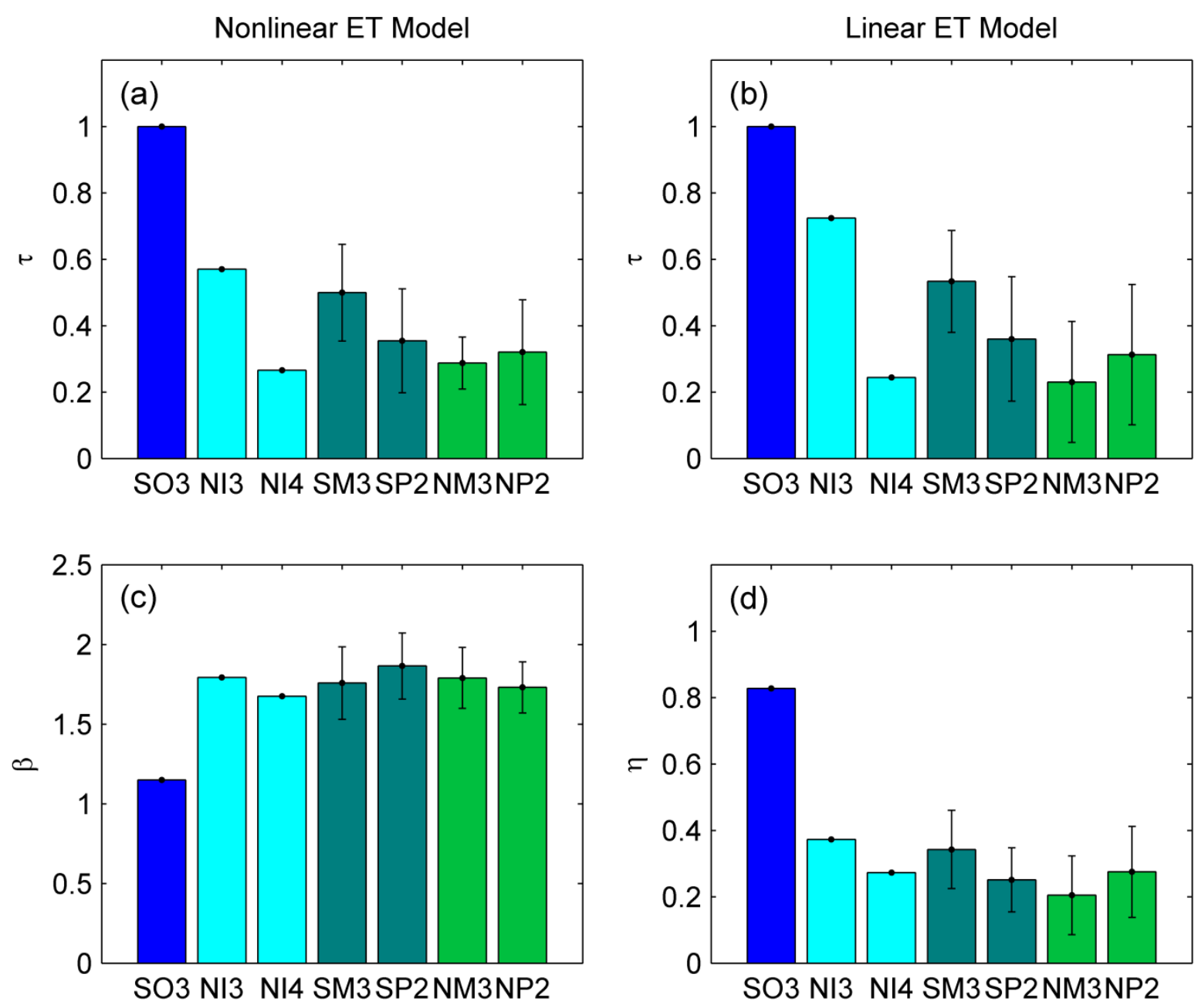

Figure 10. Calibrated values for (a) $\tau$ using the nonlinear ET model, (b) $\tau$ using the linear ET model, (c) $\beta$ using the nonlinear ET model, and (d) $\eta$ using the linear ET model at the SFS intercanopy (SO3) location, east NFS intercanopy (NI3), west NFS intercanopy (NI4), SFS mountain mahogany (SM3), SFS ponderosa pine (SP2), NFS mountain mahogany (NM3), and NFS ponderosa pine (NP2) locations. Where more than one location was simulated (under vegetation), the columns show the average parameter values, and the error bars show the spatial standard deviation of the calibrated parameter values

values for SM3 ( 0.50 for the nonlinear model; 0.53 for the linear model) are larger than the regression slope between throughfall at SM2 and SO2 (0.31). In contrast, the average values for $\tau$ at NM3 ( 0.29 for the nonlinear model; 0.23 for the linear model) are lower than the regression slope at NM2 (0.44). All estimates of the throughfall fraction for mountain mahogany fall within the range of roughly $25 \%$ to $50 \%$. The average values of $\tau$ under the ponderosa pines are 
similar to those under the mountain mahogany, but they fall within a narrower range. The average values for $\tau$ at SP2 (0.35 for the nonlinear model; 0.36 for the linear model) and NP2 ( 0.32 for the nonlinear model; 0.31 for the linear model) are only slightly lower than the regression slope between NP2 and $\mathrm{SO} 2$ (0.41). Overall, the throughfall fractions that are inferred from the soil moisture observations are similar to the values estimated from the rain gauge data after accounting for the loss associated with the litter layer $(\sigma)$.

Figure 10c shows the calibrated values for $\beta$, which is used in the nonlinear ET model, at each location. The value for $\beta$ at SO3 is lower than all other locations, which implies that this location has higher ET rates for a given soil moisture than the other locations. The values for $\beta$ at all other locations are all greater than one. Initially, this result is surprising because Pierce (1958) and Entekhabi et al. (1992) suggest that, for vegetated locations, $\beta$ is less than one and smaller than for bare soil. However, the apparent contradiction can be explained by the shallow depth considered here. For shallow soil moisture, soil evaporation is the primary component of ET. When vegetation is present, ET is reduced due to the shading, which requires $\beta>1$. If a deeper soil layer is considered, transpiration might be the primary component of ET. In that case, the presence of vegetation would increase ET relative to a bare location, which would imply $\beta<1$. It is interesting that the $\beta$ value at SM3 is similar to the other sites because the PET under the SFS mountain mahogany was about double the PET for the sites on the NFS. The similarity suggests that the soil moisture probe locations at SM3 might receive less insolation than the pyranometer for under the SFS mountain mahogany. Overall, however, the observed soil moisture dynamics are consistent with the notion that shading from vegetation reduces the ET loss from the shallow soil layer. 
The calibrated values for $\eta$, which is used in the linear ET model, are shown in Figure 10d. The value for $\eta$ at SO3 (0.83) is the highest among all locations. The high value is expected because no shading occurs at this location, and it suggests a large portion of the total PET is utilized for ET from the modeled soil layer. The value of $\eta$ also likely depends on the assumption that $\beta=1$ (Lowry (1959) reports $\beta>1$ for areas of bare soil). The $\eta$ values at all other locations are considerably lower, indicating that much less of the PET is used for ET from the modeled soil layer. The values for $\eta$ at both intercanopy locations $(0.37$ at NI3 and 0.27 at NI4) are a bit larger than the regression slope between the PET at NI2 and SO2 (0.22). Considering the mountain mahogany, the average $\eta$ values for SM3 (0.34) and NM3 (0.20) are very close to the regression slopes between PET rates at SM2 and SO2 (0.35) and NM2 and SO2 (0.22), respectively. All estimates of $\eta$ for the mountain mahogany locations fall within the range from 0.20 to 0.40 . The average values of $\eta$ under the ponderosa pines are similar to those under the mountain mahogany, but they fall within a narrower range. The average values for $\eta$ at SP2 (0.25) and NP2 (0.28) are slightly higher than the regression slope between NP2 and SO2 (0.22). Altogether, the values for $\eta$ that are inferred from the soil moisture observations are similar to the values estimated from the regressions of the PET data, which were based on the differences in insolation. Overall, the modeling results suggest that the differences in the soil moisture dynamics between the locations can largely be explained by the observed differences in throughfall and insolation. 


\section{CHAPTER 6 CONCLUSIONS}

Several conclusions can be drawn from the results of this study. In the study catchment, interception has the strongest effect at locations that are directly under plants, but it also affects forest intercanopy locations. A majority of the rainfall at the NFS intercanopy location becomes throughfall, but the amount is inconsistent between calculation methods (a regression slope vs. the ratio of the average values). Throughfall fractions inferred from the soil moisture model suggest that lower throughfall rates might also occur in some cases. Under the mountain mahogany and ponderosa pines, a minority of rainfall becomes throughfall. A rough estimate is that $25 \%$ to $50 \%$ of rainfall becomes throughfall for the conditions observed. The throughfall under the plants is significantly less than the throughfall in the forest intercanopy, but differences in the throughfall between plant types are inconsistent between analysis methods and not statistically significant.

Shading is important and similar for all locations considered on the NFS including locations both under plants and between plants. The similarity among these points is due to the relatively thick canopy cover on this hillslope and the wide variety of sun angles that occur throughout the day and season. PET at the NFS forest intercanopy is only about $20 \%$ of the PET for the SFS open site, and this reduction is mainly due to shading rather than hillslope orientation. The lower PET on the NFS is relatively consistent between analysis methods. PET under the NFS mountain mahogany and ponderosa are also about $20 \%$ of the PET at the SFS open site. This reduction is also consistent between analysis methods.

Less shading can occur under the SFS mountain mahogany than for the locations on the NFS, but shading is still important. PET under the SFS mountain mahogany is about $40 \%$ of the PET for the SFS open site. This percentage is higher than the other vegetated sites, and the 
increase is consistent between analysis methods. It suggests that insolation is able to reach under the shrub for certain sun angles due to the short and sparse canopy on this hillslope. However, the model parameter $\beta$ for the SFS mountain mahogany is similar to the values for the other vegetation sites, which indirectly suggests that shading under other SFS mountain mahogany shrubs might be similar to the NFS.

Shallow soil moisture values at NFS intercanopy locations are higher than the SFS open site for dry conditions. This result is likely due to the shading that was described previously. Any difference between the NFS intercanopy and SFS open sites under wet conditions is inconsistent, which is likely due to spatial variations in throughfall at the NFS sites. Differences in the average soil moisture between the NFS intercanopy and SFS open sites are also inconsistent, but the NFS intercanopy sites are the same or wetter on average than the SFS open site.

Shallow soil moisture under all vegetation types considered is typically greater than soil moisture at the SFS open site for dry conditions and smaller than the SFS open site for wet conditions. This result is consistent with the lower throughfall and PET rates that occur under vegetation than in the open. Average shallow soil moisture is higher under all vegetation types than in the open. This result implies that the shading effect that occurs at this catchment is stronger than the interception effect for the conditions studied. No consistent patterns were found for the soil moisture observed at different locations under an individual plant.

In contrast to values suggested in the literature, $\beta$ is consistently higher under vegetation than at the open site. For a given soil moisture, vegetated sites have lower ET due to shading, which is represented by a higher $\beta$. This behavior is likely associated with the shallow soil layer considered, which is more affected by soil evaporation than root water uptake. 
These conclusions have several implications. In water-limited ecosystems, patchy distributions of vegetation are commonly observed with shallow soils that are typically wetter underneath the canopy than between the canopy, suggesting that a positive feedback exists between plants and soil moisture (D'Odorico et al., 2007). This feedback can affect the composition and structure of vegetation communities in semiarid environments, where wetter conditions underneath the canopy facilitate seedling establishment and growth (Lejeune et al., 2002). In many dryland ecosystems, for example, the density of woody plant cover is increasing, which may be due to the ability of plant communities to stimulate favorable growing conditions (McClaran and Angell, 2007; Potts et al., 2010). Therefore, understanding the feedback between shallow soil moisture and woody vegetation can help reduce the negative impacts of woody plant encroachment (Ratajczak et al., 2012) and yet increase the ability of land managers to stimulate reforestation. In contrast, the feedback between shallow soil moisture and vegetation is also related to desertification, which can be stronger in dryland ecosystems than in more mesic environments (D'Odorico et al., 2007). Thus, dryland ecosystems are more prone to desertification when abrupt changes occur in the distribution of vegetation (via natural or anthropogenic disturbances). In order to meet the challenges facing water-limited ecosystems, then, it is critical that a greater understanding of the interactions between woody vegetation and shallow soil moisture be reached. 


\section{BIBLIOGRAPHY}

Allen RG, Pereira L, Raes D, and Smith M. 1998. Crop evapotranspiration: guidelines for computing crop water requirements. Food and Agriculture Organization of the United Nations: Rome, Italy

Amenu GG and Kumar P. 2008. A model for hydraulic redistribution incorporating coupled soil-root moisture transport. Hydrology and Earth System Sciences 12:55-74.

Arguez A, Durre I, Applequist S, Vose RS, Squires MF, and Yin X. 2012. NOAA's 1981-2010 U.S. Climate Normals: Monthly Precipitation, Snowfall and Snow Depth. Journal of Applied Meteorology and Climatology, Submitted.

Beaumont GP and Knowles JD. 1996. Statistical Tests: An introduction with MINITAB commentary. Prentice Hall International: Englewood Cliffs, New Jersey

Beier C, Hansen K, and Gundersen P. 1993. Spatial variability of throughfall in a spruce forest. Environmental Pollution 81:257-267.DOI: 10.1016/0269-7491(93)90208-6.

Bhark EW and Small EE. 2003. Association between plant canopies and the spatial patterns of infiltration in shrubland and grassland of the Chihuahuan Desert, New Mexico. Ecosystems 6:185-196.DOI: 10.1007/s10021-002-0210-9.

Breshears DD, Nyhan JW, Heil CE, and Wilcox BP. 1998. Effects of woody plants on microclimate in a semiarid woodland: Soil temperature and evaporation in canopy and intercanopy patches. International Journal of Plant Sciences 159:1010-1017.DOI: 10.1086/314083.

Brooks JR, Meinzer FC, Coulombe R, and Gregg J. 2002. Hydraulic redistribution of soil water during summer drought in two contrasting Pacific Northwest coniferous forests. Tree Physiology 22:1107-1117.

Buczko U and Bens O. 2006. Assessing soil hydrophobicity and its variability through the soil profile using two different methods. Soil Science Society of America Journal 70:718-727.DOI: 10.2136/sssaj2005.0183.

Caldwell TG, Young MH, Zhu JT, and McDonald EV. 2008. Spatial structure of hydraulic properties from canopy to interspace in the Mojave Desert. Geophysical Research Letters 35.DOI: $10.1029 / 2008 \mathrm{~g} 1035095$.

Campbell GS. 1974. Simple method for determining unsaturated conductivity from moisture retention data. Soil Science 117:311-314.

Carsel RF and Parrish RS. 1988. Developing joint probability-distributions of soil water retention characteristics. Water Resources Research 24:755-769.DOI:10.1029/WR024i005p00755.

Cavanaugh ML, Kurc SA, and Scott RL. 2011. Evapotranspiration partitioning in semiarid shrubland ecosystems: a two-site evaluation of soil moisture control on transpiration. Ecohydrology 4:671681.DOI: 10.1002/eco.157.

Chatfield C. 1996. The analysis of time series an introduction. Chapman and Hall: London

Coleman ML and Niemann JD. 2013. Controls on topographic dependence and temporal instability in catchment-scale soil moisture patterns. Water Resources Research 49:1625-1642.DOI: $10.1002 /$ wrcr.20159.

Cosby BJ, Hornberger GM, Clapp RB, and Ginn TR. 1984. A statistical exploration of the relationships of soil-moisture characteristics to the physical properties of soils. Water Resources Research 20:682-690.DOI: 10.1029/WR020i006p00682.

D'Odorico P, Caylor K, Okin GS, and Scanlon TM. 2007. On soil moisture-vegetation feedbacks and their possible effects on the dynamics of dryland ecosystems. Journal of Geophysical ResearchBiogeosciences 112:1-10.DOI: 10.1029/2006jg000379.

Dekker LW and Ritsema CJ. 2000. Wetting patterns and moisture variability in water repellent Dutch soils. Journal of Hydrology 231:148-164.DOI: 10.1016/s0022-1694(00)00191-8.

Dingman SL. 2002. Physical Hydrology. Second edition. Waveland Press: Long Grove, Illinois 
Doerr SH, Shakesby RA, and Walsh RPD. 2000. Soil water repellency: its causes, characteristics and hydro-geomorphological significance. Earth-Science Reviews 51:33-65.DOI: 10.1016/s00128252(00)00011-8.

Dunkerley D. 2000. Hydrologic effects of dryland shrubs: defining the spatial extent of modified soil water uptake rates at an Australian desert site. Journal of Arid Environments 45:159-172.DOI: 10.1006/jare.2000.0636.

Dunne T and Black RD. 1970. Partial area contributions to storm runoff in a small New-England watershed. Water Resources Research 6:1296-1311.DOI: 10.1029/WR006i005p01296.

Entekhabi D. 1995. Recent advances in land-atmosphere interaction research. Reviews of Geophysics 33:995-1003.DOI: 10.1029/95rg01163.

Entekhabi D, Rodriguez-Iturbe I, and Bras RL. 1992. Variability in Large-Scale Water Balance with Land Surface-Atmosphere Interaction. Journal of Climate 5:798-813.DOI: 10.1175/15200442(1992)005<0798:vilswb>2.0.co;2.

Evett SR. 2000. The TACQ computer program for automatic time domain reflectometry measurements: I. Design and operating characteristics. Transactions of the Asae 43:1939-1946

Evett SR, Heng LK, Moutonnet P, and Nguyen ML. 2008. Field estimation of soil water content: A practical guide to methods, instrumentation and sensor technology. International Atomic Energy Agency: Vienna

Ford ED and Deans JD. 1978. The effects of canopy structure on stemflow, throughfall and interception loss in a young sitka spruce plantation. Journal of Applied Ecology 15:905-917.

Fry J, Xian G, Jin S, Dewitz J, Homer C, Yang L, Barnes C, Herold N, and Wickham J. 2011. Completion of the 2006 National Land Cover Database for the Conterminous United States. $P E \& R S$ 77:858-864.

Gerrits AMJ, Pfister L, and Savenije HHG. 2010. Spatial and temporal variability of canopy and forest floor interception in a beech forest. Hydrological Processes 24:3011-3025.DOI: 10.1002/hyp.7712.

Gutierrez-Jurado HA, Vivoni ER, Harrison JBJ, and Guan H. 2006. Ecohydrology of root zone water fluxes and soil development in complex semiarid rangelands. Hydrological Processes 20:32893316.DOI: 10.1002/hyp.6333.

Helvey JD. 1971. A summary of rainfall interception by certain conifers of North America. Pages 103 113 in Biological Effects in the Hydrologic Cycle: West Lafayette, IN

Jury WA and Horton R. 2004. Soil Physics. John Wiley \& Sons, Inc.: Hoboken, New Jersey

Katra I, Lavee H, and Sarah P. 2008. Rainfall distribution around shrubs: Eco-geomorphic implications for arid hillslopes. Geomorphology 95:544-548.DOI: 10.1016/j.geomorph.2007.05.016.

Keizer JJ, Ferreira AJD, Coelho COA, Doerr SH, Malvar MC, Domingues CSP, Perez IMB, Ruiz C, and Ferrari K. 2005. The role of tree stem proximity in the spatial variability of soil water repellency in a eucalypt plantation in coastal Portugal. Australian Journal of Soil Research 43:251-259.DOI: 10.1071/sr04096.

King P. 1981. Comparison of methods for measuring severity of water repellence of sandy soils and assessment of some factors that affect its measurement. Soil Research 19:275-285.DOI: 10.1071/SR9810275.

Koster RD, Dirmeyer PA, Guo ZC, Bonan G, Chan E, Cox P, Gordon CT, Kanae S, Kowalczyk E, Lawrence D, Liu P, Lu CH, Malyshev S, McAvaney B, Mitchell K, Mocko D, Oki T, Oleson K, Pitman A, Sud YC, Taylor CM, Verseghy D, Vasic R, Xue YK, Yamada T, and Team G. 2004. Regions of strong coupling between soil moisture and precipitation. Science 305:1138-1140.DOI: 10.1126/science. 1100217.

Kurc SA and Small EE. 2004. Dynamics of evapotranspiration in semiarid grassland and shrubland ecosystems during the summer monsoon season, central New Mexico. Water Resources Research 40:1-15.DOI: $10.1029 / 2004$ wr003068. 
Lauenroth WK, Urban DL, Coffin DP, Parton WJ, Shugart HH, Kirchner TB, and Smith TM. 1993. Modelling vegetation structure ecosystem process interactions across sites and ecosystems. Ecological Modelling 67:49-80.DOI: 10.1016/0304-3800(93)90099-e.

LeBlanc DC. 2004. Statistics concepts and applications for science. Jones and Bartlett: Boston, Massachusetts

Lejeune O, Tlidi M, and Couteron P. 2002. Localized vegetation patches: A self-organized response to resource scarcity. Physical Review E 66.DOI: 10.1103/PhysRevE.66.010901.

Levia DF and Frost EE. 2003. A review and evaluation of stemflow literature in the hydrologic and biogeochemical cycles of forested and agricultural ecosystems. Journal of Hydrology 274:129.DOI: 10.1016/s0022-1694(02)00399-2.

Li YQ, Sun YJ, Zhang TH, Luo WQ, Deng Y, and Liu XP. 2013. Responses of soil moisture under shrub Caragana microphylla to rainfall. Chinese Journal of Ecology 32:1097-1103

Liang WL, Kosugi K, and Mizuyama T. 2007. Heterogeneous soil water dynamics around a tree growing on a steep hillslope. Vadose Zone Journal 6:879-889.DOI: 10.2136/vzj2007.0029.

Lowry WP. 1959. The falling rate phase of evaporative soil-moisture loss - a critical evaluation. Bulletin of the American Meteorological Society 40:605-608.

Ludwig JA, Wilcox BP, Breshears DD, Tongway DJ, and Imeson AC. 2005. Vegetation patches and runoff-erosion as interacting ecohydrological processes in semiarid landscapes. Ecology 86:288297.DOI: 10.1890/03-0569.

McClaran MP and Angell DL. 2007. Mesquite and grass relationships at two spatial resolutions. Plant Ecology 191:119-126.DOI: 10.1007/s11258-006-9220-6.

Moran MS, Hamerlynck EP, Scott RL, Stone JJ, Collins CDH, Keefer TO, Bryant R, DeYoung L, Nearing GS, Sugg Z, and Hymer DC. 2010. Hydrologic response to precipitation pulses under and between shrubs in the Chihuahuan Desert, Arizona. Water Resources Research 46:1-12.DOI: 10.1029/2009wr008842.

Murphy SR, Lodge GM, and Harden S. 2004. Surface soil water dynamics in pastures in northern New South Wales. 3. Evapotranspiration. Australian Journal of Experimental Agriculture 44:571583.DOI: 10.1071/ea03041.

Newman BD, Campbell AR, and Wilcox BP. 1997. Tracer-based studies of soil water movement in semiarid forests of New Mexico. Journal of Hydrology 196:251-270.DOI: 10.1016/s00221694(96)03320-3.

Niemann JD and Eltahir EAB. 2004. Prediction of regional water balance components based on climate, soil, and vegetation parameters, with application to the Illinois River Basin. Water Resources Research 40:1-14.DOI: 10.1029/2003wr002806.

Omernik JM. 1987. Ecoregions of the conterminous United States. Annals of the Association of American Geographers 77:118-125

Pariente S. 2002. Spatial patterns of soil moisture as affected by shrubs, in different climatic conditions. Environmental Monitoring and Assessment 73:237-251.DOI: 10.1023/a:1013119405441.

Pierce LT. 1958. Estimating seasonal and short-term fluctuations in evapotranspiration from meadow crops. Bulletin of the American Meteorological Society 39:73-79.

Potts DL, Scott RL, Bayram S, and Carbonara J. 2010. Woody plants modulate the temporal dynamics of soil moisture in a semi-arid mesquite savanna. Ecohydrology 3:20-27.DOI: 10.1002/eco.91.

Pressland AJ. 1976. Soil-moisture redistribution as affected by throughfall and stemflow in an arid zone shrub community. Australian Journal of Botany 24:641-649.DOI: 10.1071/bt9760641.

Priestley CHB and Taylor RJ. 1972. On the assessment of surface heat flux and evaporation using large scale parameters. Monthly Weather Review 100:81-92.DOI: 10.1175/15200493(1972)100<0081:OTAOSH>2.3.CO;2.

Ratajczak Z, Nippert JB, and Collins SL. 2012. Woody encroachment decreases diversity across North American grasslands and savannas. Ecology 93:697-703

Roy JL and McGill WB. 2002. Assessing Soil Water Repellency Using the Molarity of Ethanol Droplet (Med) Test. Soil Science 167:83-97. 
Sansoulet J, Cabidoche Y-M, Cattan P, Ruy S, and Simunek J. 2008. Spatially distributed water fluxes in an andisol under banana plants: Experiments in three-dimensional modeling. Vadose Zone Journal 7:819-829.DOI: 10.2136/vzj2007.0073.

Schnabel S, Pulido-Fernandez M, and Lavado-Contador JF. 2013. Soil water repellency in rangelands of Extremadura (Spain) and its relationship with land management. Catena 103:53-61.DOI: 10.1016/j.catena.2011.11.006.

Segoli M, Ungar ED, Giladi I, Arnon A, and Shachak M. 2012. Untangling the positive and negative effects of shrubs on herbaceous vegetation in drylands. Landscape Ecology 27:899-910.DOI: 10.1007/s10980-012-9736-1.

Tripp DR and Niemann JD. 2008. Evaluating the parameter identifiability and structural validity of a probability-distributed model for soil moisture. Journal of Hydrology 353:93-108.DOI: 10.1016/j.jhydrol.2008.01.028.

Verheijen FGA and Cammeraat LH. 2007. The association between three dominant shrub species and water repellent soils along a range of soil moisture contents in semi-arid Spain. Hydrological Processes 21:2310-2316.DOI: 10.1002/hyp.6760.

Voigt GK. 1960. Distribution of rainfall under forest stands. Forest Science 6:2-10.

Wilcox BP, Breshears DD, and Turin HJ. 2003. Hydraulic conductivity in a pinon-juniper woodland: Influence of vegetation. Soil Science Society of America Journal 67:1243-1249. 